\title{
Therapeutic strategies to target the Ebola virus life cycle
}

\section{Thomas Hoenen (1) ${ }^{1,4 *}$, Allison Groseth ${ }^{2,4}$ and Heinz Feldmann (10 ${ }^{3 *}$}

Abstract | Following the Ebola virus disease epidemic in west Africa, there has been increased awareness of the need for improved therapies for emerging diseases, including viral haemorrhagic fevers such as those caused by Ebola virus and other filoviruses. Our continually improving understanding of the virus life cycle coupled with the increased availability of 'omics' analyses and high-throughput screening technologies has enhanced our ability to identify potential viral and host factors and aspects involved in the infection process that might be intervention targets. In this Review we address compounds that have shown promise to various degrees in interfering with the filovirus life cycle, including monoclonal antibodies such as ZMapp, mAb114 and REGN-EB3 and inhibitors of viral RNA synthesis such as remdesivir and TKM-Ebola. Furthermore, we discuss the general potential of targeting aspects of the virus life cycle such as the entry process, viral RNA synthesis and gene expression, as well as morphogenesis and budding.
Haemorrhagic fever A disease that is characterized by fever and in severe cases associated with bleeding manifestations as a result of dysregulated coagulation and/or damage to the blood vessels.
${ }^{1}$ Institute of Molecular Virology and Cell Biology, Friedrich-Loeffler-Institut, Insel Riems, Greifswald, Germany.

2Junior Research Group Arenavirus Biology, Friedrich-Loeffler-Institut, Insel Riems, Greifswald, Germany.

${ }^{3}$ Laboratory of Virology, Division of Intramural Research, National Institute of Allergy and Infectious Diseases, National Institutes of Health, Hamilton, MT, USA.

${ }^{4}$ These authors contributed equally: Thomas Hoenen,

Allison Groseth

*e-mail: thomas.hoenen@fli.de; feldmannh@niaid.nih.gov

https://doi.org/10.1038/ s41579-019-0233-2
Filoviruses are a family of viruses that contains the genera Ebolavirus, Marburgvirus, Dianlovirus, Striavirus and Thamnovirus and the proposed genus Cuevavirus ${ }^{1,2}$. Ebolaviruses currently encompass six species: Zaire ebolavirus (Ebola virus (EBOV)), Sudan ebolavirus (Sudan virus), Bundibugyo ebolavirus (Bundibugyo virus), Tai Forest ebolavirus (Taï Forest virus), Reston ebolavirus (Reston virus (RESTV)) and the putative species Bombali ebolavirus (Bombali virus). In contrast, all other genera each contain only a single species: Marburg marburgvirus (Marburg virus (MARV) and Ravn virus), Mengla dianlovirus (Měnglà virus), Xilang striavirus (Xīlăng virus), Huangjiao thamnovirus (Huángjiāo virus) and Lloviu cuevavirus (Lloviu virus), respectively. Many filoviruses cause haemorrhagic fever in humans, with case fatality rates of $34-81 \%$, although there are also filoviruses such as RESTV that seem to be apathogenic in humans ${ }^{3}$. Bats are considered to be the natural hosts for filoviruses ${ }^{4}$, and outbreaks are initiated either by transmission directly from bats to humans or through an intermediate host such as non-human primates (NHPs), with human-to-human transmission then occurring via close and direct physical contact with patients or infected bodily fluids (reviewed in REFS ${ }^{5,6}$ ). Other animal species such as pigs are also susceptible to infection, but whether they have any role in transmission remains unclear ${ }^{7}$. Infection with pathogenic filoviruses results in a severe acute disease characterized by the rapid onset of generalized symptoms such as fever, headache and myalgia, as well as frequent gastrointestinal symptoms, which in severe cases progresses to a systemic infection that results in multiorgan failure and in many cases death ${ }^{8}$. The pathogenesis associated with filovirus disease is complex and seems to be the result of a combination of immune suppression and cytokine dysregulation (cytokine storm), as well as coagulation abnormalities and vascular dysfunction (reviewed in $\mathrm{REFS}^{9-12}$ ). Human pathogenic filoviruses were believed to exclusively occur in central Africa, with cases elsewhere being due to exportation of infected animals or travel of people from these endemic areas. However, the recent Ebola virus disease (EVD) epidemic from 2013 to 2016 has shown that human pathogenic filoviruses also occur in west Africa. Similarly, serological studies suggest that filoviruses could also be much more widely distributed in Asia than initially thought, as filovirusspecific antibodies have been detected in animals in Indonesia $^{13}$, Singapore ${ }^{14}$ and China ${ }^{15}$. In addition, recent genetic evidence indicates that previously unknown filovirus species exist. Full-length or nearly full-length sequences for novel filoviruses (Lloviu virus, Bombali virus and Měnglà virus) have recently been found in bats in Europe ${ }^{16,17}$, west Africa ${ }^{18}$ and China ${ }^{2}$, respectively, although no infectious viruses have yet been isolated. Therefore, the pathogenic potential of these viruses, if they exist in nature, is unknown. Furthermore, partial sequences of filovirus genomes have been reported in bat and fish samples from China ${ }^{19,20}$, which suggests that the genetic diversity of filoviruses might be greater than previously appreciated. This presents a challenging situation for the development of classic virus-targeting prophylactic and therapeutic approaches.

In general, therapeutic approaches for viral diseases can be divided into directly or indirectly acting 


\section{Box 1 | Towards a filovirus vaccine}

Despite progress in the development of candidate therapeutic strategies, treatment options are limited. Vaccinations are considered to be an important strategy to control filovirus outbreaks. Currently, several vaccine candidates against Ebola virus disease are under development (reviewed in REFS ${ }^{165-169}$ ). Candidate vaccines include non-vectored vaccines such as DNA vaccines, subunit vaccines and virus-like particle vaccines, but also vectored vaccines such as recombinant human and chimpanzee-derived adenoviruses, respiroviruses and rhabdoviruses expressing the Ebola virus (EBOV) surface glycoprotein (GP; which is one of the major antigenic determinants of the virus), as well as a modified vaccinia Ankara virus that expresses three different filovirus GPs and one nucleoprotein. The vaccine candidate that has advanced the furthest in testing is based on a recombinant vesicular stomatitis virus (rVSV) expressing GP (rVSV-EBOV; also known as rVSV $\triangle \mathrm{G}-E B O V$ GP or rVSV-ZEBOV) (reviewed in REF ${ }^{170}$ ). This vaccine was tested in high-risk individuals during the final stages of the 2013-2016 west African Ebola virus disease epidemic as part of a ring trial (that is, contacts and contacts of contacts of an infected patient have been vaccinated). No new cases were reported when the vaccine was delivered to close contacts of a person in whom the disease had been diagnosed ${ }^{33}$. As a consequence, this vaccine was used experimentally during two subsequent outbreaks, and more than 154,000 people have been vaccinated in the latest outbreak in the Democratic Republic of the Congo as of July 2019, with preliminary data indicating a protective efficacy of $97 \%^{34}$. The use of rVSV-EBOV for postexposure prophylaxis is controversially discussed. Even though some data show preliminary efficacy in non-human primate models ${ }^{171,172}$, further studies still have to confirm the benefit of the vaccine in postexposure prophylaxis.

antivirals, and host-directed therapies. Antiviral therapies either directly target viral components or processes, for example the viral polymerase (and thus virus genome replication and transcription), or inhibit virus infection indirectly by impairing host factor activity or the interaction of viral factors with these host factors. Ideally, directly acting antivirals affect only the virus without impairing host processes, which reduces adverse effects. However, directly acting antivirals are more susceptible to the development of resistance, as mutations in viral target sites can sometimes arise rapidly, particularly in the case of RNA viruses with high polymerase error rates $^{21}$. By contrast, if proviral host factors are targeted, viral mutations will usually not affect the interaction of the drug with its host target; however, there is an increased chance of adverse effects, as impairment of many host processes is detrimental for the cell itself. In the context of acute EBOV infections such effects are potentially mitigated by the relatively short timeframe required for treatment, as the acute phase of filovirus infections lasts only about 2 weeks, although the virus seems to be able to persist much longer in immune privileged $\operatorname{sites}^{11}$. In contrast to antivirals, host-directed therapies specifically modulate the host response to the virus in a beneficial way, either by aiding the host in combating the virus (for example by immune stimulation) or by ameliorating disease processes in the host without interfering with the virus ${ }^{22}$. As classic host-directed therapies do not target the viral life cycle, we will not further discuss those approaches in this Review. However, it is worth noting that as many viruses themselves modulate the host response to benefit viral replication, the line between indirect antivirals and host-directed therapies is not always clear-cut.

Numerous antiviral therapies have been approved. However, these antiviral therapies target only a very limited range of viral pathogens, with the majority being directed against HIV or hepatitis $\mathrm{C}$ virus (reviewed in $\mathrm{REF}^{23}$ ). For negative-sense RNA viruses, approved therapies are currently available only for rabies virus, respiratory syncytial virus and influenza virus ${ }^{23,24}$. Evidently, a disconnect exists between the number and variety of compounds that are being studied in the laboratory and those that have advanced to clinical testing and licensure. However, exploring the viral processes targeted by successfully approved therapies thus far can provide some insights into the viability of the different steps of the life cycle as antiviral targets for other viruses. Inhibitors of viral nucleic acid synthesis are the best represented class of antiviral drugs ${ }^{23}$. Viral protease inhibitors have also been successful for HIV and hepatitis C virus ${ }^{23}$, but they are unlikely to be applicable to the inhibition of filoviruses as these viruses lack a protease. However, individual instances of approved inhibitors of virus entry (targeting HIV, rabies virus and respiratory syncytial virus) as well as uncoating inhibitors (targeting influenza virus) and inhibitors of virus particle morphogenesis (targeting variola virus) or release (targeting influenza virus) suggest the potential to successfully target viral processes other than nucleic acid synthesis and viral protein cleavage. Furthermore, the increasing success of combination therapies, as indicated by their prevalence among recent drug approvals ${ }^{23,24}$, suggests that such approaches also need to be considered for other viruses, including filoviruses, not only to combat issues of escape but also to increase treatment efficacy.

Prompted by the devastating EVD epidemic in west Africa, which caused more than 11,000 deaths among the approximately 28,500 cases and had a crippling effect on everyday life and the economy in the affected countries, there has been a surge in research efforts to combat filovirus infections ${ }^{25,26}$. This has included research aimed at postexposure treatments (reviewed in $\mathrm{REF}^{27}$ ). Nevertheless, despite notable efforts and the promise shown by some candidate therapeutic compounds, treatment options are still limited and focus mainly on supportive measures. In outbreak settings these include fluid and electrolyte management and symptomatic treatment (for example, for fever, pain and gastrointestinal complications) as well as antimalarials and antibio$\operatorname{tics}^{28}$. However, during the west African EVD epidemic a number of experimental therapies were also tested (reviewed in REFS ${ }^{29,30}$ ), and in the two most recent EVD outbreaks in the Democratic Republic of the Congo continuing efforts have focused on monoclonal antibodies (ZMapp, mAb114 and REGN-EB3) and remdesivir $(\text { GS-5734 })^{31,32}$. Nevertheless, evidence for efficacy of these approaches is still lacking. In addition, preventive vaccinations have been assessed and proved effective as a containment measure when used in a ring vaccination strategy $^{33,34}(\mathrm{BOX} 1)$.

Concurrent with the surge in filovirus research precipitated by the west African EVD epidemic, there has also been progress in the number and variety of tools available to study filoviruses, including those of relevance for the identification and characterization of therapeutic approaches (BOX 2). Many of these tools are based on reverse genetics, which forms the basis for life cycle modelling systems used as screening tools for both host 


\section{Box 2 | Overview of in vitro model systems}

The discovery and testing of new antiviral approaches relies on the availability of tools to facilitate both initial screening (often on a large scale) and studies exploring the underlying mechanism of action. For filoviruses the establishment of various life cycle modelling systems over the past two decades has provided a robust set of tools for the initial steps of compound screening and mechanistic studies (reviewed in REFS ${ }^{119,173}$ ). These systems use genome analogues (called 'minigenomes') in which viral genes have been removed and replaced by an easily assayable reporter gene, and recapitulate some or all of the steps in the virus life cycle, depending on which viral proteins are supplied to reconstitute these activities. If only the ribonucleoprotein (RNP) complex components are supplied (that is, in a minigenome assay; see the figure, part a), only viral RNA synthesis (transcription and replication) occurs. By contrast, if the RNP complex proteins as well as the viral proteins VP40,
$\mathrm{GP}_{1,2}$ and VP24 are supplied (that is, in a transcription- and replicationcompetent virus-like particle assay; see the figure, part b), then virus-like particles containing minigenomes in place of the viral genome can be produced and used to infect new cells, thereby modelling the complete virus life cycle. The most advanced of these systems uses a tetracistronic minigenome encoding not only the reporter gene but also the viral genes necessary for morphogenesis and budding of infectious virions or virus-like particles, and allows modelling of multiple infectious cycles ${ }^{71,174}$. Other approaches to model entry include the use of pseudotyped retroviral or rhabdoviral particles carrying the filovirus glycoprotein $\mathrm{GP}_{1,2}$, or recombinant vesicular stomatitis virus encoding a filovirus glycoprotein in place of its own glycoprotein ${ }^{175,176}$ (see the figure, part c). All these approaches have in common that they can be used without the need for a maximum containment laboratory.

\section{a Minigenome system}

Minigenome: $\mid$ rep

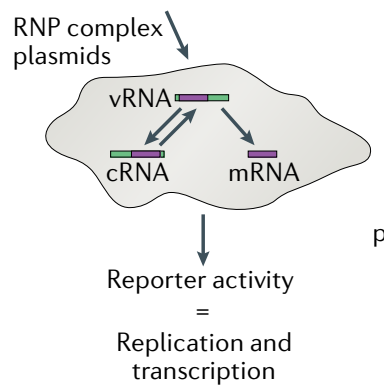

b Transcription- and replication-competent virus-like particle system

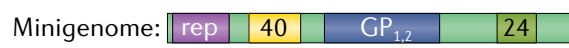

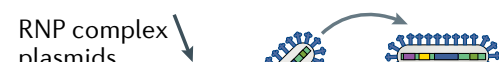

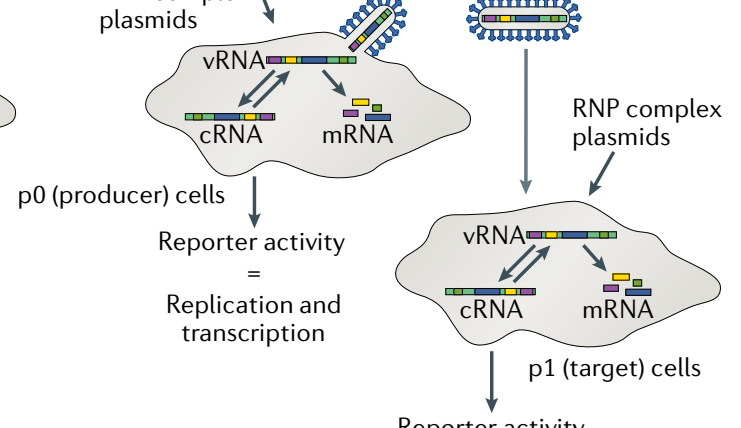

Reporter activity

$=$

Replication, transcription, budding and entry

\section{c Pseudotyped retroviral vectors}

Helper plasmids for production of reporter-expressing retroviral vectors

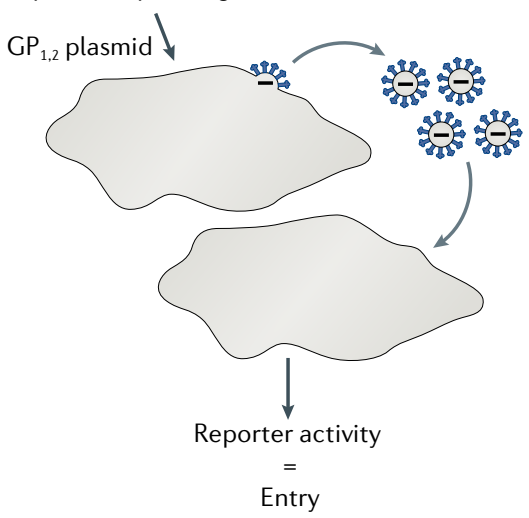

cRNA, antigenomic RNA; rep, reporter gene; vRNA, viral genomic RNA.

factors important for filoviruses ${ }^{35,36}$ and antivirals ${ }^{36-40}$ and recombinant reporter-expressing viruses, which allow faster and easier quantification of the efficacy of antivirals $^{41-43}$. Similar progress has been made in the development of animal models, which are a prerequisite for the preclinical stages of therapeutic development. The predictive power of these animal models relies on the ability to authentically recapitulate important features of human disease, with mice being a good initial screening model with limited predictive power, and NHPs being the gold standard animal model (reviewed in REFS ${ }^{44-46}$ ) (BOX 3).

In this Review, we first provide an overview of the EBOV life cycle and then explore existing therapeutic approaches and novel concepts for targeting EBOV infections. In particular, we address key stages of the virus life cycle (that is, entry, viral RNA synthesis, and morphogenesis and budding) and discuss how both viral and host components involved in these processes can be exploited as potential antiviral targets, for example by antibodies interfering with the viral entry process, or small-molecule inhibitors of viral RNA synthesis. Importantly, although most of our knowledge regarding filovirus molecular biology comes from studies on EBOV, and to some extent MARV, it is generally thought that most findings can be transferred to other family members, although subtle differences almost certainly exist, particularly with respect to the potential humanapathogenic filoviruses. Thus, most of the concepts discussed should be applicable to other filoviruses.

\section{The filovirus life cycle}

Filoviruses are non-segmented negative-sense RNA viruses with seven genes ${ }^{1}$ (FIG. 1 a). In virions, the genome is found in nucleocapsids and is encapsidated by the nucleoprotein NP, and is further associated with the polymerase L, the polymerase cofactor VP35 and the transcriptional activator VP30 (REF. ${ }^{47}$ ). Together these nucleocapsid components are also called the 'ribonucleoprotein (RNP) complex components'. Nucleocapsids further interact with the nucleocapsid-associated protein VP24 (REF. ${ }^{48}$ ), and they are surrounded by the matrix space with the sole matrix protein VP40, which drives virus particle morphogenesis and budding ${ }^{49}$. Finally, the viral glycoprotein $\mathrm{GP}_{1,2}$ is embedded in the host cell-derived envelope and consists of two subunits $\mathrm{GP}_{1}$ and $\mathrm{GP}_{2}$ that are proteolytically produced from a precursor molecule ${ }^{50}$.

Filoviruses follow a life cycle (FIG. 1 b) typical for cytoplasmically replicating negative-sense RNA viruses. Attachment (FIG. 2) to the target host cell can be facilitated by various attachment host factors, including the asialoglycoprotein receptor ${ }^{51}$, lectins 
Box 3 | Overview of in vivo model systems

Validation of in vitro results for prospective therapeutic approaches relies on the availability of a range of animal models (reviewed in REFS ${ }^{44-46}$ ). The laboratory mouse ${ }^{177,178}$ remains the first-line model for testing of therapeutics, given its convenience, its low cost and the array of molecular tools available (see the table). However, its predictive power for success in non-human primates or humans is low, and it requires the use of rodent-adapted virus variants. In recent years, mouse models have been substantially advanced. For example, both Collaborative Cross and humanized mice (reviewed in REF ${ }^{44}$ ) better recapitulate the coagulation abnormalities associated with human disease following infection with wild-type (non-adapted) virus variants. However, their availability is limited and the reliability of these mouse strains for therapeutic testing remains to be experimentally demonstrated. Secondary small and medium-sized animal models for drug evaluation were until recently limited to the guinea pi $^{179}$, but now also include both the hamster model ${ }^{180,181}$ and the ferret model ${ }^{182}$ (of note, ferrets do not seem to be suitable disease models for Marburg virus infection ${ }^{183}$ ). Unlike the guinea pig model, the hamster and ferret models demonstrate coagulopathy, and ferrets also exhibit coagulopathy after infection with the wild-type virus. The non-human primate model ${ }^{184}$, based on infection of either rhesus or cynomolgus macaques, remains the gold standard for the demonstration of both safety and efficacy of antivirals at the preclinical stage as both authentically model human disease after infection with wild-type viruses. In particular, the rhesus macaque model may be preferred for therapeutic evaluation as the disease progression is delayed, providing a therapeutic window more similar to that in humans.

\begin{tabular}{|c|c|c|c|c|c|c|c|}
\hline Characteristic & $\begin{array}{l}\text { Standard } \\
\text { laboratory } \\
\text { mouse }\end{array}$ & $\begin{array}{l}\text { Collaborative } \\
\text { Cross (RIX) } \\
\text { mouse }\end{array}$ & $\begin{array}{l}\text { Humanized } \\
\text { mouse }\end{array}$ & Guinea pig & Hamster & Ferret & Macaque \\
\hline Cost & Low & Low & Moderate & $\begin{array}{l}\text { Low to } \\
\text { moderate }\end{array}$ & $\begin{array}{l}\text { Low to } \\
\text { moderate }\end{array}$ & Moderate & Very high \\
\hline Availability & High & Low & Low & High & High & High & Low \\
\hline $\begin{array}{l}\text { Coagulation } \\
\text { abnormalities }\end{array}$ & No & $\begin{array}{l}\text { Yes (strain } \\
\text { dependent) }\end{array}$ & Yes & No & Yes & Yes & Yes \\
\hline Virus strain & $\begin{array}{l}\text { Adapted } \\
\text { (mouse) }\end{array}$ & Wild-type & Wild-type & $\begin{array}{l}\text { Adapted } \\
\text { (guinea pig) }\end{array}$ & $\begin{array}{l}\text { Adapted } \\
\text { (mouse or } \\
\text { hamster) }\end{array}$ & Wild-type & Wild-type \\
\hline $\begin{array}{l}\text { Predictive } \\
\text { power }\end{array}$ & Low & Unknown & Unknown & Moderate & Unknown & Unknown & High \\
\hline
\end{tabular}

RIX, recombinant interbred intercrossed.

(DC-SIGN, L-SIGN, human macrophage galactoseand $\mathrm{N}$-acetylgalactosamine-specific C-type lectin) ${ }^{52-54}$, $\beta 1$ integrins $^{55}$, human folate receptor- $\alpha^{56}$, members of the TYRO3 receptor tyrosine kinase family ${ }^{57}$ and TIM1 $\left(\mathrm{REF}^{58}{ }^{58}\right.$ ), although none of them are essential in all relevant cell types. Although in most cases attachment is mediated by $\mathrm{GP}_{1,2}$, in the case of TIM1 phosphatidylserines in the virus envelope rather than $\mathrm{GP}_{1,2}$ interact with the host attachment factor, giving rise to the idea that filoviruses use apoptotic mimicry for their entry to at least some extent $^{59,60}$. After attachment, virions are taken up mainly by macropinocytosis into endolysosomes ${ }^{61,62}$. Following acidification of the endolysosome the filovirus surface glycoprotein $\mathrm{GP}_{1,2}$ is cleaved by host cathepsins into the fusion-active form $\mathrm{GP}_{\mathrm{CL}}\left(\mathrm{REF}^{6}{ }^{63}\right)$, which interacts with the obligate host receptor NPC1 to trigger fusion of the viral and endolysosomal membranes ${ }^{64-67}$. Recently, the twopore channel TPC2 has also been shown to be important for the entry process, although its exact role remains a matter of debate ${ }^{68,69}$. Fusion facilitates release of the nucleocapsids into the cytoplasm. Although details of the uncoating process are not well studied, it has been proposed that dissociation of the RNP complexassociated protein VP24 following fusion allows the relaxation of rigid nucleocapsids into transcription- and replication-competent RNP complex structures ${ }^{70,71}$.

Primary transcription occurs in the cytoplasm of infected cells, resulting in the production of a first wave of all viral mRNAs, which are translated and supplement the RNP complex components brought into the cell within the virus particles during infection, thereby supporting further secondary transcription of viral mRNAs as well as genome replication (FIG. 3). In ebolavirus species, genome transcription is facilitated by the RNP complex proteins NP, VP35, VP30 and $\mathrm{L}^{72}$. By contrast, VP30 has been shown to be dispensable for transcription of short templates in MARV (that is, minigenomes; see BOX 2), although the protein remains necessary for rescue of recombinant virus from full-length genomic templates ${ }^{73,74}$. Production of viral proteins, particularly of NP, leads to the formation of inclusion bodies, which are the sites of genome replication and presumably also transcription $^{75,76}$. In the case of ebolaviruses and most likely also cuevaviruses, several mRNA species that encode different forms of the glycoprotein are generated by transcriptional editing by $\mathrm{L}$, which results in the production of both the virion-associated $\mathrm{GP}_{1,2}$ and two soluble glycoproteins, sGP and ssGP ${ }^{77,78}$. A number of host factors have a role in replication and transcription. In particular, DNA topoisomerase 1 (TOP1) supports EBOV RNA synthesis and has been shown to directly interact with the viral polymerase, and it was also proposed that TOP1 interacts with viral RNA structures ${ }^{79}$. Similarly, the RNA-binding protein Staufen 1 has been shown to interact with the viral RNA termini as well as NP, VP35 and VP30, and has been proposed to have an important role in both initiation and termination of RNA synthesis ${ }^{80}$. Recently, a genome-wide small interfering 
a

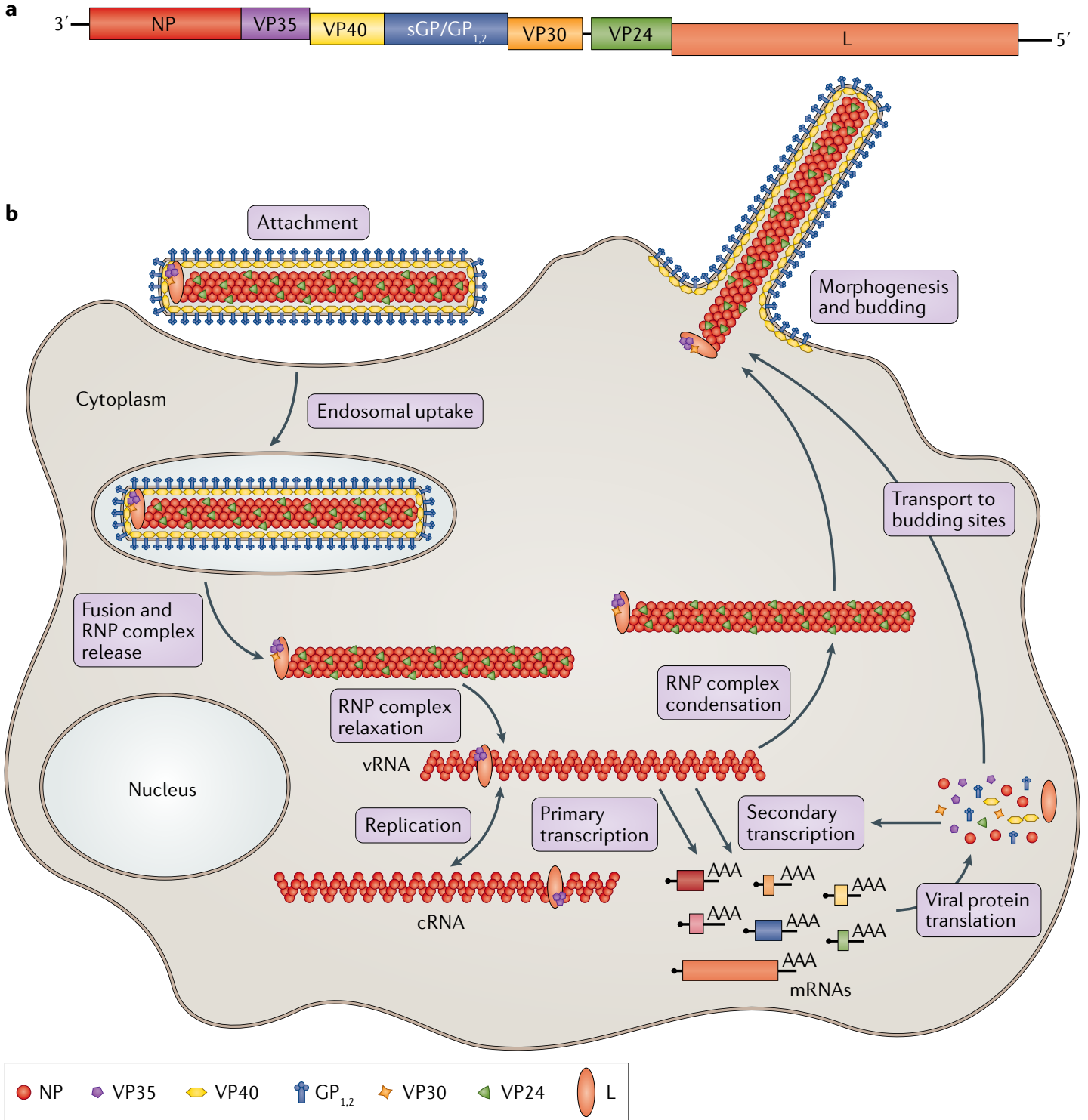

Fig. 1 | Ebola virus genome structure and life cycle. a | Ebola viruses are non-segmented negative-sense RNA viruses. The proteins encoded in the genome are the nucleoprotein NP, the polymerase cofactor VP35, the matrix protein VP40, the non-structural soluble glycoprotein sGP, the structural glycoprotein $\mathrm{GP}_{1,2}$, the transcriptional activator VP30, the nucleocapsid-associated protein VP24 and the polymerase L. Intergenic and terminal non-coding regions are indicated by black lines, and the offset steps indicate gene overlaps. $\mathbf{b}$ | The viral genome is encapsidated by NP and associated with L, VP35 and VP30 (forming the ribonucleoprotein (RNP) complex). Nucleocapsids are further associated with VP24, and they are surrounded by VP40. The glycoprotein $\mathrm{GP}_{1,2}$ is embedded in the host cell-derived envelope. Attachment of virions at the cell surface is followed by uptake via macropinocytosis into endolysosomes. Subsequently, the virus envelope fuses with the endolysosomal membrane and RNP complexes are released into the cytoplasm, where they relax and become transcriptionally active. Primary transcription is facilitated by viral RNP complex proteins brought into the cell, and viral mRNAs are translated into proteins by host ribosomes. The newly synthesized viral proteins facilitate secondary transcription and genome replication, copying the viral genomic RNA (vRNA) through an antigenomic intermediate (cRNA). Newly formed RNP complexes condense into a packaging-competent form and are transported to budding sites, where morphogenesis and budding occurs in a process mediated by VP40. Part $\mathbf{b}$ is adapted with permission from REF. ${ }^{185}$, Springer Nature Limited.

RNA (siRNA) screen identified the RNA splicing and export factors NXF1 and DDX39B in promoting EBOV replication and/or transcription and/or viral RNA translation, although the underlying mechanisms remain unclear $^{35}$. Host factors also have an important role in regulating the balance of replication and transcription by modulating the phosphorylation status of VP30
$\left(\mathrm{REF}^{81}\right)$, which in its phosphorylated state is inactive in supporting transcription but becomes rapidly dephosphorylated and thus activated on entering inclusion bodies ${ }^{76}$. Dephosphorylation of VP30 is regulated through its interaction with protein phosphatase $2 \mathrm{~A}$ $(\mathrm{PP} 2 \mathrm{~A})^{82}$, a host cell phosphatase that is recruited to RNP complexes by EBOV $\mathrm{NP}^{83}$. A recent study identified the 


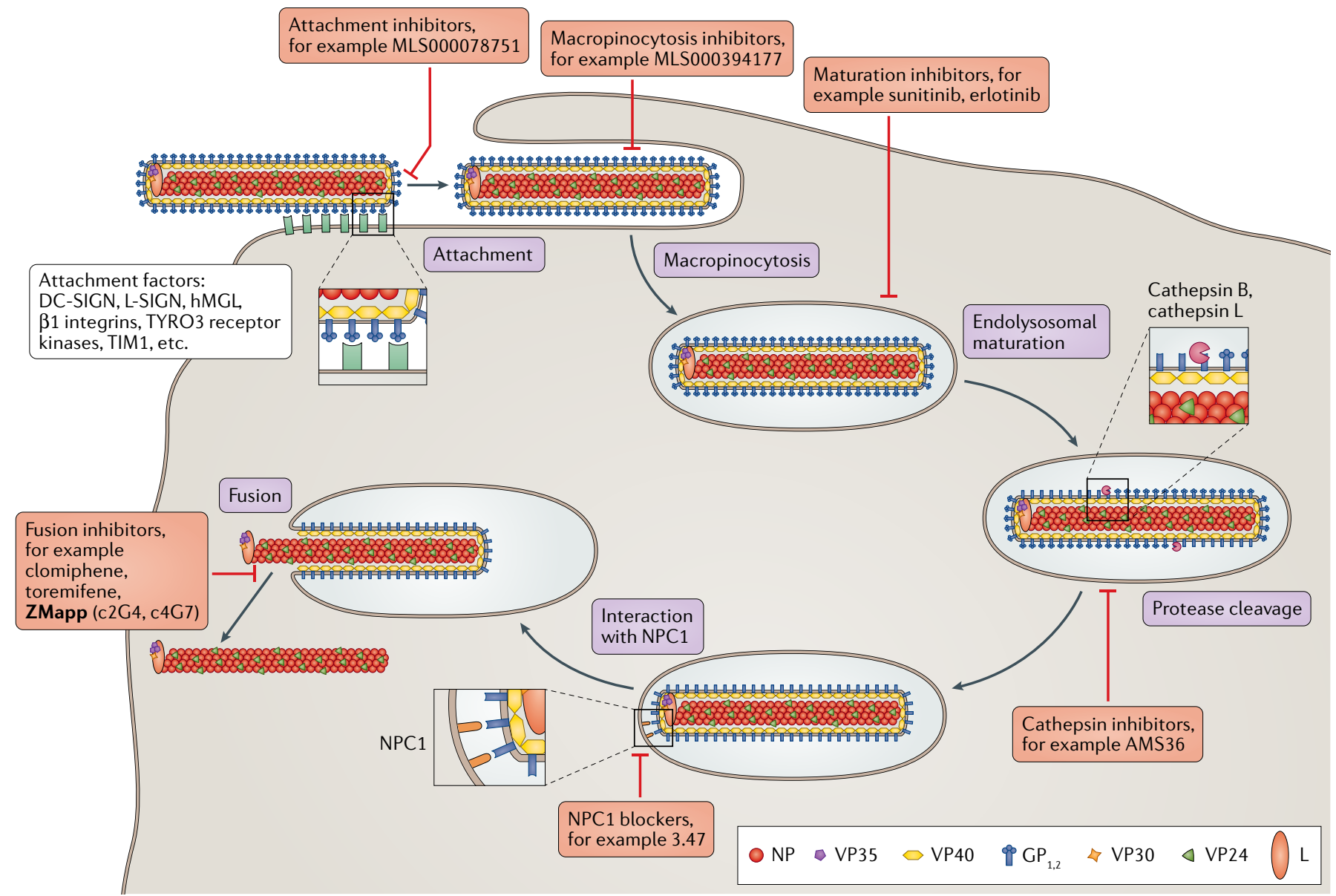

Fig. 2 Inhibitors of the viral entry process. Attachment at the cell surface can be mediated by interaction of virions with a number of cellular attachment factors, such as asialoglycoprotein receptor, various lectins (DC-SIGN, L-SIGN or human macrophage galactose- and $N$-acetylgalactosamine-specific $C$-type lectin (hMGL)), $\beta 1$ integrins, human folate receptor- $\alpha$, members of the TYRO3 receptor tyrosine kinases and TIM1. This interaction is mostly mediated by the viral surface glycoprotein $\mathrm{GP}_{1,2}$, or in the case of TIM1 via phosphatidylserine in the virus envelope. Virions are taken up by macropinocytosis into endolysosomes. Maturation of endolysosomes results in a drop in $\mathrm{pH}$ and the activation of cathepsins, which cleave $\mathrm{GP}_{1,2}$ into the fusion-active form $\mathrm{GP}_{\mathrm{CL}}$. $\mathrm{GP}_{\mathrm{CL}}$ is able to interact with the cellular receptor NPC1, which results in fusion of the viral and endolysosomal membranes, and release of ribonucleoprotein complexes into the cytoplasm. Attachment, macropinocytosis, endolysosome maturation, cathepsin-mediated cleavage, NPC1 binding and fusion can be inhibited by antivirals, examples of which are indicated in red boxes. Of note, ZMapp (highlighted in bold) is currently in clinical trials. Adapted with permission from REF. ${ }^{185}$, Springer Nature Limited.

Secretory pathway A pathway composed of the endoplasmic reticulum, Golgi apparatus, lysosome and cell membrane (as well as the vesicles that transit between them) and responsible for the secretion of proteins into the extracellular environment.

Multivesicular bodies A specialized type of late endosomes that contain internal membrane-bound vesicles formed by budding of the endosomal membranes into their lumen. cellular protein RBBP6, which inhibits the PP2A-NP interaction by mimicking the binding interface on NP, and peptides corresponding to this region were able to impair EBOV in vitro by suppressing viral RNA synthesis $^{84}$. These findings highlight that this interaction is a potential antiviral target. Furthermore, VP30 is also dephosphorylated by the host protein phosphatase 1 , although the molecular mechanism underlying this interaction remains unclear ${ }^{85}$.

Current data suggest that at late stages of RNA synthesis VP24 facilitates condensation of the RNP complexes into replication- and transcription-inactive but packaging-competent nucleocapsids through its physical association with the RNP complex ${ }^{70,71}$. These nucleocapsids are then transported to the cell surface in an actin-dependent manner ${ }^{86,87}$ (FIG. 4). The filovirus matrix protein VP40 is also transported to the cell surface, and has been reported to interact with a number of cellular trafficking components such as $\operatorname{actin}^{88,89}$, microtubules ${ }^{90,91}$, IQGAP1 (REF. ${ }^{92}$ ) and COPII ${ }^{93}$. By contrast, the filovirus glycoprotein is transported to the cell surface through the secretory pathway, where it is post-translationally modified by the addition of both $\mathrm{O}$-linked and $\mathrm{N}$-linked glycans ${ }^{94}$, as well as furinmediated cleavage into the mature $\mathrm{GP}_{1}$ and $\mathrm{GP}_{2}$ subunits ${ }^{50}$. Unlike for many other viruses, this cleavage is not essential for biological activity of the glycoprotein ${ }^{95,96}$.

Virion assembly occurs at the plasma membrane and is coordinated by VP40. Again, a number of host factors have an important role in this process, particularly those of the endosomal sorting complex required for transport (ESCRT), which usually is involved in the generation of multivesicular bodies. VP40 directly interacts with ESCRT components such as TSG101 (REFS ${ }^{97,98}$ ) and various ubiquitin ligases ${ }^{98-100}$ through its late-domain motifs, and these host proteins play an important part in the budding 


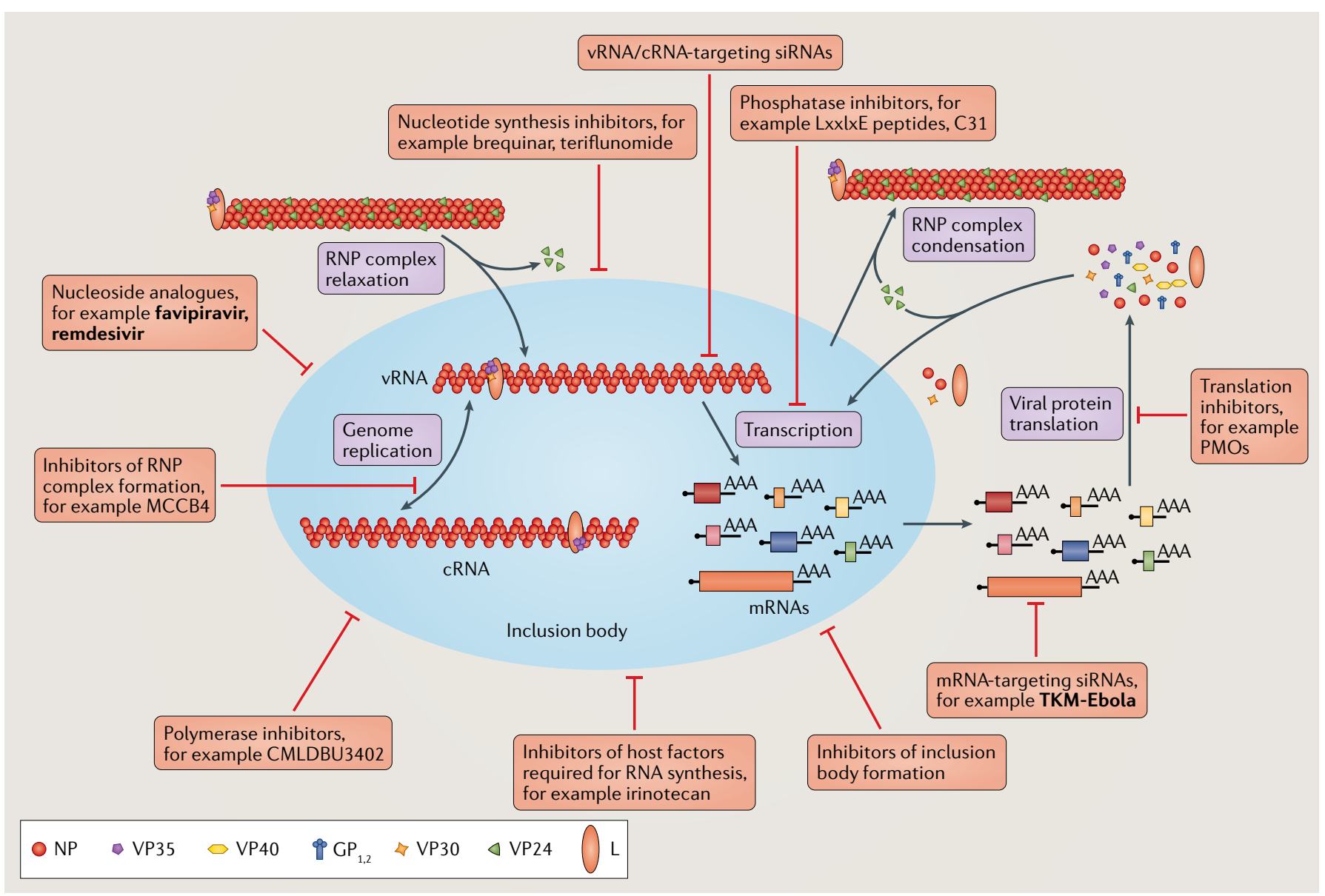

Fig. 3 | Targeting viral RNA transcription and replication. Once in the cytoplasm, ribonucleoprotein (RNP) complexes relax and primary transcription ensues. The generated viral mRNAs are translated into viral proteins by host ribosomes. Newly synthesized viral proteins facilitate secondary transcription, as well as genome replication, which occurs in inclusion bodies. Replicated genomes in the form of RNP complexes condense and are transported to budding sites. Multiple classes of drugs can impair viral RNA synthesis, particularly nucleoside analogues, nucleotide synthesis inhibitors and polymerase inhibitors. During genome replication nascent viral genomic RNAs (vRNAs) and antigenomic RNAs (cRNAs) are encapsidated by NP, a process that can be impaired by inhibitors of RNP complex formation. Finally, mRNAs as well as vRNAs or cRNAs can function as targets for small interfering RNAs (siRNAs), and translation of viral mRNAs can be blocked by phosphorodiamidate morpholino oligonucleotides (PMOs). Of note, although most of the strategies aimed at targeting viral RNA transcription and translation remain in the experimental and developmental stages, the nucleoside analogues favipiravir and remdesivir and the siRNA TKM-Ebola (highlighted in bold) are currently in clinical trials or have been experimentally used in humans.

process. For MARV VP40, tyrosine phosphorylation of VP40 by host kinases has been shown to be important for packaging of RNP complexes into budding virions ${ }^{101}$. Finally, interaction of EBOV $\mathrm{GP}_{1,2}$ with host scramblases enhances exposure of phosphatidylserine on the outer envelope of virions, which is a prerequisite for binding to phosphatidylserine receptors such as TIM1 during entry ${ }^{102}$.

\section{Antiviral strategies}

Targeting the entry process. Targeting the entry process (FIG. 2) is the furthest developed avenue of development of antivirals against filoviruses. Most importantly, several glycoprotein-targeting antibodies (particularly ZMapp, mAb114 and REGN-EB3) are currently in clinical trials and are being used during outbreaks ${ }^{31}$. This is somewhat surprising as early attempts at antibody therapy in NHP models (for an overview of the different animal models see BOX 3) were mostly unsuccessful, even when neutralizing antibodies were used (reviewed in REF. ${ }^{103}$ ). However, whole IgG purified from convalescent serum of macaques that survived EBOV challenge following vaccination proved protective, despite limited neutralization in vitro ${ }^{104}$. Subsequent work thus focused on antibody cocktails rather than individual antibodies, and eventually gave rise to ZMapp, which consists of three mouse-human chimeric antibodies and is protective in the NHP model even if therapy is started after onset of symptoms ${ }^{105}$. In a human clinical trial towards the end of the west African EVD epidemic, ZMapp showed a posterior probability of $91.2 \%$ to be superior to the current standard of care alone ${ }^{106}$. Considerable work has since been done to better understand the mechanism of action of these antibody cocktails and what features predict the ability of antibodies to confer protection ${ }^{107}$. The results of these studies show that ZMapp contains two antibodies 


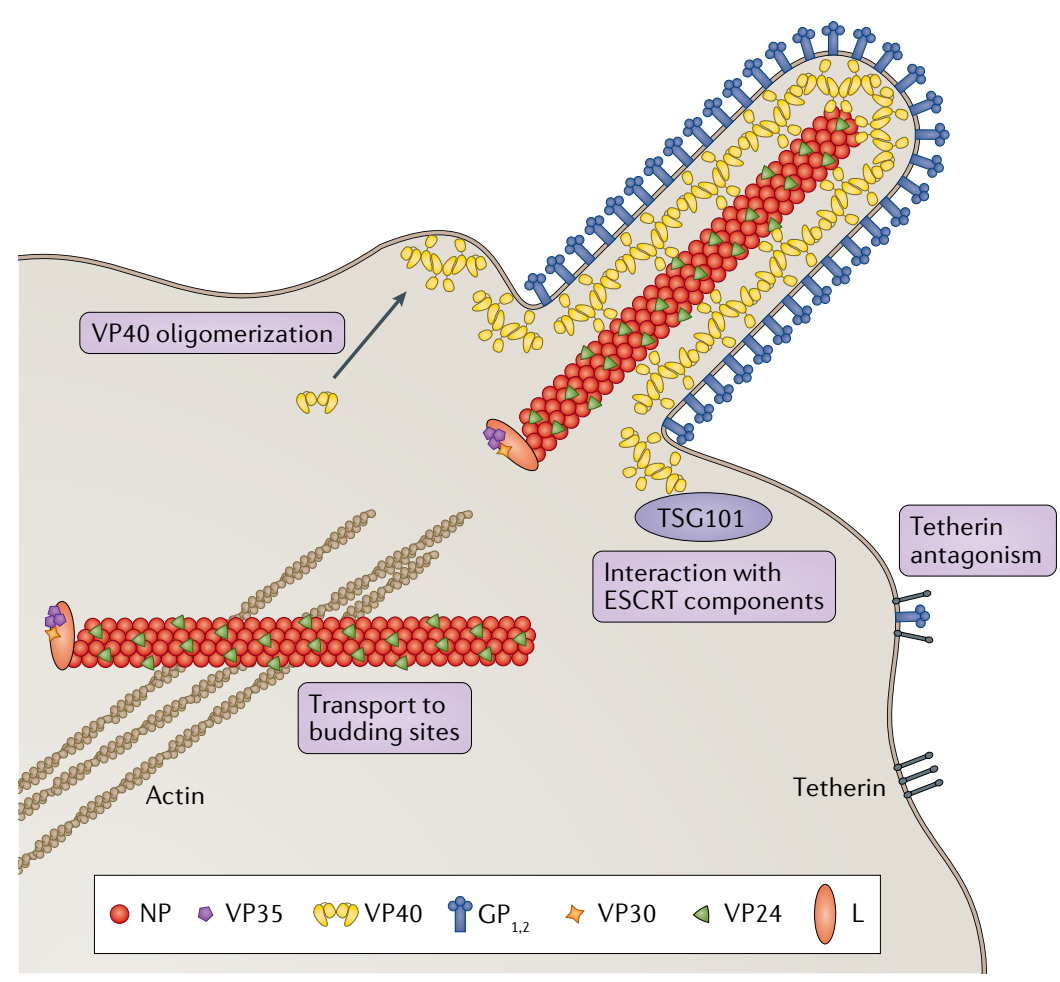

Fig. 4 | Theoretical targets in the morphogenesis and budding process. Viral components are transported to budding sites through various mechanisms, including interactions with the actin cytoskeleton. At budding sites, morphogenesis and budding is coordinated by the viral protein VP40. This process is dependent on both oligomerization of VP40 and its interaction with host cell factors of the endosomal sorting complex required for transport (ESCRT), such as the ESCRT component TSG101. The viral glycoprotein $\mathrm{GP}_{1,2}$ antagonizes the host factor tetherin, which allows budded viral particles to be released from the cell. To date, no inhibitors of individual processes have been described; however, all these steps represent theoretical targets for antivirals.

(c2G4 and c4G7) with strong neutralizing activity ${ }^{108,109}$. These antibodies bind close to the $\mathrm{GP}_{1}-\mathrm{GP}_{2}$ interface in a region that is not removed during cathepsin cleavage, and are thought to cause neutralization by blocking structural changes in $\mathrm{GP}_{\mathrm{CL}}$ necessary for the fusion process. In addition, ZMapp contains a non-neutralizing antibody (c13C6), which binds both sGP and $\mathrm{GP}_{1,2}$, and is thought to facilitate antibody-dependent cell-mediated cytotoxicity ${ }^{110}$. In contrast to ZMapp, mAb114, the second antibody-based treatment currently being used during outbreaks, is a single monoclonal antibody with strong neutralizing activity that binds both $\mathrm{GP}_{1,2}$ and $\mathrm{sGP}^{111,112}$. It was cloned from memory $B$ cells of a patient who survived EVD and binds to an epitope spanning both the glycan cap (similar to the binding site of c13C6, with which $\mathrm{mAb} 114$ competes for glycoprotein binding) and the $\mathrm{GP}_{1}$ core $^{112}$. However, in contrast to $\mathrm{c} 13 \mathrm{C} 6$ it remains able to bind cathepsin-cleaved $\mathrm{GP}_{\mathrm{CL}}$, and thus exerts neutralizing activity by blocking interaction with NPC1. In addition, it also elicits substantial antibody-dependent cell-mediated cytotoxicity, and thus it seems to combine properties of the three different antibodies in ZMapp. The final antibody cocktail currently being tested in the Democratic Republic of the Congo, REGN-3B (also known as REGN3470-3471-3479), contains three monoclonal antibodies with different properties: neutralizing with immune effector function (such as inducing antibody-dependent phagocytosis or antibodydependent cell-mediated cytotoxicity) but no sGP binding; non-neutralizing with immune effector function and sGP binding; and neutralizing without immune effector function and no sGP binding ${ }^{113}$. Thus, it seems that antibodies (or antibody cocktails) have to combine several different properties to be protective, and a recent systematic study of 171 monoclonal antibodies revealed that at least both neutralization and immune effector function are requirements for protection ${ }^{114}$. Current efforts focus on the development of cross-protective antibodies targeting multiple filovirus species, which would be beneficial not only because it would reduce the number of therapies that would have to be developed for use in humans but also because it would potentially allow deployment against novel pathogenic filoviruses ${ }^{115,116}$. Furthermore, production and cost issues for therapeutic antibodies are being addressed ${ }^{117}$. One issue that might also have to be considered with respect to glycoprotein-targeting antibodies is the possibility of escape mutations, which were observed during treatment of NHPs with an anti-EBOV antibody cocktail ${ }^{118}$.

Small-molecule entry inhibitors have also been extensively investigated, and the vast majority of candidate therapeutic compounds are directed against this process (Supplementary Table 1). This might be because high-throughput screening-compatible systems to model virus entry have been readily available for more than a decade in the form of recombinant or pseudotyped viruses bearing filovirus glycoproteins, and more recently also in the form of transcription- and replication-competent virus-like particle systems (BOX 2). Furthermore, even in screens that assess effects on the whole virus life cycle there seems to be a bias towards the identification of entry inhibitors. For example, during a screen of 2600 FDA-approved drugs using infectious EBOV, 25 of the 30 hits targeted the entry process ${ }^{42}$. However, the use of life cycle modelling systems (BOX 2) that model steps in the virus life cycle other than entry can help circumvent this issue $\mathrm{e}^{37,119}$.

Given the large number of compounds that have been identified, it is not surprising that virtually every aspect of the entry process has been targeted. Targeting the first steps of virus uptake, two inhibitors of cell surface attachment (MLS000078751 and MLS000534476) and two inhibitors of macropinocytosis (MLS000394177 and MLS000733230) have recently been identified on the basis of a screen of 319,855 small molecules and show in vitro efficacy against $\mathrm{EBOV}^{120}$. However, data on their in vivo efficacy have not yet been reported (for information regarding the efficacy in tissue culture and in various animal models for all small compounds mentioned in this Review, see Supplementary Table 1). Compounds such as apilimod and the FDA-approved drugs colchicine, sunitinib and erlotinib (among others) have been reported to impair trafficking and maturation of the endolysosome, thus preventing entry ${ }^{120,121}$. Although sunitinib and erlotinib alone showed no significant protection in a mouse model, combinations of these drugs seem to function in a synergistic fashion and show modest protection ${ }^{122}$. Tetrandrine, an inhibitor 
of TPC2 that blocks EBOV entry and is partially protective in vivo in a lethal mouse model, has also been suggested to inhibit endolysosome maturation ${ }^{69}$, although another report suggested that it functions after glycoprotein cleavage and NPC1 interaction ${ }^{68}$, and thus its exact mechanism of action is still a matter of debate. Cleavage of the glycoprotein in the endolysosome by cathepsins can be blocked by several cathepsin inhibitors, for example AMS36 and its derivatives, which have been shown to be highly efficient in in vitro studies and are currently under investigation in animal models ${ }^{123}$. The subsequent interaction of $\mathrm{GP}_{\mathrm{CL}}$ with NPC1 can also be impaired, and indeed one of the first reports of NPC1 as a receptor for EBOV was due to its identification as the target of the EBOV inhibitor 3.47 during a small-molecule screen ${ }^{66}$. Although this inhibitor has unfavourable properties for in vivo application, derivatives have now been developed that will allow future in vivo testing ${ }^{124}$. Finally, a number of compounds inhibit fusion by destabilizing the prefusion conformation of $\mathrm{GP}_{\mathrm{CL}}$. The most prominent of these compounds are the FDA-approved selective oestrogen receptor modulators toremifene and clomiphene ${ }^{125,126}$, although for clomiphene an inhibition of $\mathrm{Ca}^{2+}$ influx into the endolysosome has also been proposed as an alternative mechanism of action ${ }^{127}$. The protective in vivo effect of these drugs alone was good for clomiphene ( $90 \%$ survival in the mouse model) but only modest in the case of toremifene (50\% survival), and they seem to have strong synergistic effects with other drugs ${ }^{121,128,129}$. However, further testing in more stringent animal models and clinical studies is lacking, and thus there is insufficient evidence regarding the potential therapeutic benefit of single entry inhibitor-based approaches.

Finally, although not directly functioning as entry inhibitors, statins also seem to affect the viral glycoprotein. A recent study showed that they inhibit $\mathrm{GP}_{1}$ maturation and thus reduce the levels of $\mathrm{GP}_{1}$ in virions, and in vitro a wide range of statins have shown efficacy against $\mathrm{EBOV}^{130}$. However, there is no reliable information regarding the efficacy of statins in animal models or humans.

Targeting the viral RNA synthesis machinery. Strategies to target viral RNA synthesis (FIC. 3) include both representatives that directly target viral components of the RNA synthesis machinery and those that target cellular contributors to the RNA synthetic process. Both approaches have shown considerable potential, and indeed the viral replication machinery can be considered to be a very promising target, although our lack of knowledge regarding the cellular factors that contribute to viral RNA synthesis in EBOV continues to hamper progress.

Some of the earliest reported approaches to show success in targeting the viral replication machinery involved the use of RNA interference to achieve either siRNAmediated degradation of viral mRNAs (TKM-Ebola) ${ }^{131}$ or phosphorodiamidate morpholino oligomer (PMO)mediated translational blocking of viral protein production $^{132}$. Whereas TKM-Ebola was developed on the basis of targeting of a combination of three viral gene products (VP35, VP24 and L), PMO-based approaches were found to be most successful in animal models, including NHPs, when targeting VP24 (AVI-6002 and AVI-7537). Although this is not necessarily intuitive, recent evidence indicating an important role for VP24 in nucleocapsid condensation ${ }^{70,71}$ suggests that in addition to targeting critical RNP complex components (for example, VP35 and L) this step in the virus life cycle also may be a target for intervention. Alternatively, interfering with the roles of both VP35 and VP24 in interferon antagonism ${ }^{12}$ has to be considered as an additional possible mechanism of action of those compounds. In principle, in vitro work has suggested that direct siRNA-mediated targeting of some regions of the viral genome may also be possible ${ }^{132,133}$, but this approach has so far not been advanced further.

More recently, direct targeting of the viral polymerase complex with small compounds has also shown great promise in vitro. For instance, on the basis of a screen of vesicular stomatitis virus polymerase inhibitors, the indoline alkaloid-type compound CMLDBU3402 was identified and shown to inhibit EBOV transcription ${ }^{134}$, although it remains unclear if the compound interacts with the viral polymerase complex directly or through a cellular host factor. Also, a small-molecular inhibitor (MCCB4) was recently developed on the basis of structure-guided chemistry using the crystal structure of NP, which is an essential component of the RNP complex $^{135}$. This compound inhibits viral RNA synthesis by blocking a hydrophobic pocket on NP that is capable of forming intramolecular contacts with either a flexible arm of NP or VP35. Similarly, compounds that inhibit EBOV RNA synthesis by preventing activating dephosphorylation of the viral transcriptional activator VP30 by host cell phosphatases have also recently been developed. These include an LxxIxE motif-containing peptide inhibitor that blocks recruitment of PP2A to VP30 by $\mathrm{NP}^{83}$, as well as the cyclopentane quinolonederivative C31, which inhibits dephosphorylation of VP30 by protein phosphatase $1\left(\mathrm{REF}^{85}{ }^{85}\right.$. However, all of these approaches that directly target the polymerase or other RNP complex components have so far been assessed only in vitro.

One approach to targeting the RNA synthetic machinery that has been comparatively well explored involves the use of nucleoside analogues (for example, favipiravir (T-705), remdesivir (GS-5734), BCX4430, $\beta$-D- $N^{4}$-hydroxycytidine or balapiravir) ${ }^{136-140}$ and inhibitors of host cell nucleotide synthetic pathways (for example, merimepodib, mycophenolate, SW835, brequinar or teriflunomide) $)^{35,38,121,141}$, specifically those controlling synthesis of GTP, UTP and CTP. Depletion of the nucleotide pools that supply the essential building blocks of new RNA synthesis and the incorporation of potentially mutagenic analogues with the resulting potential for error catastrophe are likely to be mechanisms of action of these compounds. Furthermore, for GTP inhibitors such as merimepodib and mycophenolic acid one must consider possible effects on the many GTP-dependent host cell processes and enzymes, some of which may function as proviral factors. For some viruses these nucleoside analogue compounds have also shown evidence of direct inhibition of the viral polymerase ${ }^{142-144}$ and, indeed, remdesivir functions as a nucleoside 
analogue that leads to delayed chain termination of the nascent $\mathrm{RNA}^{145}$. Importantly, remdesivir, which is one of the compounds currently in clinical trials in the Democratic Republic of the Congo, shows selectivity for viral polymerases over mammalian polymerases that is determined by two defined ten-amino acid motifs in the polymerase, and this compound has broad activity against a number of viruses ${ }^{145,146}$.

Unfortunately, with the exception of the aforementioned examples, only a few studies have focused specifically on targeting the (mostly unidentified) host factors involved in supporting viral RNA synthesis. However, the involvement of host cell proteins both in the formation of inclusion bodies ${ }^{147,148}$ and in the RNP complexes themselves ${ }^{80}$ and evidence that EBOV RNA synthesis relies on a number of components of the host cell replication and mRNA processing and export machinery ${ }^{35,79}$ suggest a number of potentially attractive targets. For example, the anticancer drug irinotecan impairs EBOV propagation, presumably through its ability to inhibit TOP1, which interacts with the EBOV L protein and supports viral RNA synthesis through its phosphodiester bridge-cleaving and recombination activities ${ }^{79}$.

Although most of the strategies aimed at targeting viral RNA synthesis remain in the experimental or developmental stages, a few have progressed to clinical evaluation, and in particular, TKM-Ebola and favipiravir were examined as part of phase II clinical trials during the west African EVD epidemic ${ }^{149-151}$. For favipiravir the study outcomes were not unanimous, with one study showing no benefit for severe cases of EVD and no clear conclusion for mild to moderate cases of $\mathrm{EVD}^{150}$, whereas another study suggested a benefit for all patients but acknowledged some limitations to study design and execution ${ }^{151}$. These included imbalances in the baseline characteristics of groups (for example, age or viral load at onset of treatment), the fact that the study was nonrandomized and non-blinded, and the fact that $72 \%$ of the participants opted to be transferred to different treatment facilities within 2 days of the start of treatment, resulting in changes in the therapeutics they received. Therefore, further randomized controlled trials will be necessary to reach a conclusion as to the efficacy of favipiravir in patients. For TKM-Ebola, only patients with very high viral loads participated in the study, and for these patients no benefit could be shown, but no information regarding effects in mild to moderate cases of EVD is available. Remdesivir is also beginning to be evaluated clinically, including during the recent outbreak in the Democratic Republic of the Congo in 2018; however, no peer-reviewed results from this trial are currently available ${ }^{31}$. Finally, the adenosine nucleoside analogue BCX4430 is now being advanced to phase I testing ${ }^{137}$.

Targeting morphogenesis and budding. In contrast to entry and viral RNA synthesis, few compounds targeting morphogenesis or budding (FIG. 4) have been identified, and no compound is known to be protective in an animal model. However, in a recent high-content imaging screen two compounds, D011-2120 and G202-0362, were identified to inhibit egress of the bunyavirus Rift Valley fever virus and also to be active against EBOV and MARV in vitro, although the mechanism has not yet been established ${ }^{152}$. Furthermore, in a recent screen using the transcription- and replication-competent virus-like particle system, bisacodyl was identified as a potential budding inhibitor, but details regarding its mode of action are lacking ${ }^{36}$. However, its function as a laxative likely precludes the use of bisacodyl in patients with EVD. Finally, nilotinib, an ABL1 tyrosine kinase inhibitor, was shown to inhibit both EBOV and MARV by impairing phosphorylation of tyrosine residues in VP40, and thus potentially inhibiting the packaging of RNP complexes into budding virions ${ }^{101,153}$.

However, despite the low number of identified drugs, theoretical considerations suggest a number of antiviral targets in morphogenesis and budding that could be exploited for therapy: to reach budding sites, viral proteins and nucleocapsids have to be transported to the cell surface. Whereas $\mathrm{GP}_{1,2}$ is transported through the secretory pathway ${ }^{154}$, VP40 and nucleocapsids are transported in the cytoplasm. In the case of nucleocapsids, transport is actin dependent ${ }^{87}$, whereas for VP40 the transport mode to the cell surface is less clear, as components of numerous distinct cellular trafficking systems have been found to interact with this protein (see the section 'The filovirus life cycle').

Once all viral components have reached the cell surface, budding is coordinated by VP40. Interactions with ESCRT proteins are important for this process, and molecular targets on VP40 that are involved in those interactions exist in the form of late domains ${ }^{98,100}$. However, budding can still occur independently of these late domains, albeit with reduced efficiency ${ }^{96,155}$. Furthermore, there seems to be redundancy between individual late-domain motifs and access points into the ESCRT pathway, and hence it is not clear whether inhibiting a single VP40-ESCRT interaction will constitute a viable antiviral approach. By contrast, oligomerization of VP40 seems to be essential for budding, and the molecular interfaces necessary for VP40 oligomerization are very well defined ${ }^{156,157}$. Thus, VP40 oligomerization might constitute a better target for antivirals that would have the potential to completely abolish budding.

Finally, tetherin has been identified as a cellular antiviral factor that anchors budding virions to the cell surface, and its action is counteracted by EBOV $\mathrm{GP}_{1,2}\left(\mathrm{REFS}^{158-160}\right)$. Indeed, in the context of infectious EBOV, little effect of overexpressed tetherin has been observed $^{161,162}$, which suggests that EBOV is able to overcome the block imposed by tetherin. However, the molecular mechanism for this tetherin antagonism is not yet clear, although it seems to involve both subunits of the glycoprotein ${ }^{160,163}$ and specifically a GxxxA motif in the transmembrane domain of $\mathrm{GP}_{2}\left(\mathrm{REF}^{163}\right)$. Similarly, whether overcoming glycoprotein-mediated tetherin antagonism would constitute a viable approach for filovirus treatment remains unclear as in vivo data are lacking.

Overall, more detailed knowledge of the mechanisms of both RNP complex and VP40 transport, as well as VP40 oligomerization and GP-mediated tetherin antagonism, and particularly a better structural understanding of the interactions involved in these processes are urgently 
needed. This will help identify appropriate molecular targets and support the development of therapeutic approaches aiming at inhibiting budding and morphogenesis, and will thus allow targeting of multiple aspects of the virus life cycle simultaneously, potentially increasing therapy efficiency and reducing the probability of resistance development.

\section{Conclusions and open questions}

Despite many recent advances in the development of therapeutic strategies for filovirus infections, treatment needs still remain largely unmet. With the exception of the monoclonal antibodies, for most of the compounds discussed in this Review only in vitro data are available or, in some instances, data based on the mouse model, which is known to have a low predictive value for efficacy in humans (BOX 3). Nevertheless, the urgency created by the EVD epidemic in west Africa resulted in the use of some of these compounds in patients on a compassionate use basis. Unfortunately, many of the clinical trial and compassionate use data are difficult to interpret due to underpowered patient numbers, questionable trial design and poor execution. However, this might change with the ongoing outbreak in the Democratic Republic of the Congo, where a randomized controlled trial is under way in EVD treatment centres in the health zones with the highest case numbers (Katwa, Beni and Butembo $)^{164}$.

Nevertheless, we now need to thoroughly evaluate the efficacy of the most promising compounds that have been identified in vitro over the last few years and provide missing preclinical data using animal models that are more predictive of the efficacy in humans (BOX 3), taking into consideration the data from the currently ongoing trials. This will allow more informed decisionmaking for future clinical trials and deployment of (experimental) therapies. In parallel, the search for novel treatment concepts needs to continue with state-of-the art technologies and tools, and knowledge gaps that are particularly obvious when it comes to host factors involved in the virus life cycle need to be addressed.
Exploring combination therapies that target various steps of a single or multiple aspect of the virus life cycle might also prove to be a viable strategy. Such an approach might not only allow the use of drugs with less than optimal efficacy as monotherapies but also has the potential for the use of lower individual drug doses, thereby facilitating dose sparing and reducing toxicity, as well as alleviating problems associated with the development of drug resistance. Of similar importance, costs and logistical issues such as transport, storage and administration of drugs have to be addressed. The availability of an inexpensive small-molecule antiviral would be of tremendous benefit during an outbreak, and is probably the most practical solution. Oral availability of such a drug would be highly desirable, but alternative effective delivery routes would be beneficial for proper dosing in the case of gastrointestinal complications, which are often associated with EVD.

Finally, future outbreaks may be caused by unknown filoviruses that are refractory to current vaccines and traditional virus-directed therapeutic strategies, especially those based on antibodies. Thus, more attention has to be given to the development of broadly active intervention strategies. This can be achieved either by identifying conserved features within filoviruses that can function as antiviral targets or by targeting host factors commonly used by all filoviruses, or even a wider range of viruses. Particularly, perusing the latter strategy might avoid many of the challenges associated with the classic 'one-bug-one-drug' approach, including those posed by novel virus species and the limited economic viability of therapies for many viral diseases.

Despite these remaining challenges, the last few years have seen tremendous progress in the development of both therapeutics to counter filovirus infections and the tools necessary to identify and characterize them. Thus, although a great amount of work still lies ahead of us, we are getting closer to the development of an effective treatment for this devastating disease.

Published online 24 July 2019
1. Burk, R. et al. Neglected filoviruses. FEMS Microbiol. Rev. 40, 494-519 (2016).

2. Yang, X. L. et al. Characterization of a filovirus (Mengla virus) from Rousettus bats in China. Nat. Microbiol. 4 390-395 (2019).

3. Miranda, M. E. \& Miranda, N. L. Reston ebolavirus in humans and animals in the Philippines: a review. J. Infect. Dis. 204 (Suppl. 3), S757-S760 (2011).

4. Schuh, A. J., Amman, B. R. \& Towner, J. S. Filoviruses and bats. Microbiol. Aust. 38, 12-16 (2017).

5. Vetter, P. et al. Ebola virus shedding and transmission: review of current evidence. J. Infect. Dis. 214 S177-S184 (2016)

6. Judson, S., Prescott, J. \& Munster, V. Understanding Ebola virus transmission. Viruses 7, 511-521 (2015)

. Fischer, K. et al. Serological evidence for the circulation of ebolaviruses in pigs From Sierra Leone. J. Infect. Dis. 218, S305-S311 (2018).

8. Kortepeter, M. G., Bausch, D. G. \& Bray, M. Basic clinical and laboratory features of filoviral hemorrhagic fever. J. Infect. Dis. 204 (Suppl. 3), S810-S816 (2011).

9. Hoenen, T., Groseth, A., Falzarano, D. \& Feldmann, H. Ebola virus: unravelling pathogenesis to combat a deadly disease. Trends Mol. Med. 12, 206-215 (2006).

10. Bixler, S. L. \& Goff, A. J. The role of cytokines and chemokines in filovirus infection. Viruses 7 5489-5507 (2015)
11. Baseler, L., Chertow, D. S., Johnson, K. M., Feldmann, H $\&$ Morens, D. M. The pathogenesis of Ebola virus disease. Annu. Rev. Pathol. 12, 387-418 (2017)

12. Messaoudi, I., Amarasinghe, G. K. \& Basler, C. F. Filovirus pathogenesis and immune evasion: insights from Ebola virus and Marburg virus. Nat. Rev. Microbiol. 13, 663-676 (2015).

13. Nidom, C. A. et al. Serological evidence of Ebola virus infection in Indonesian orangutans. PLOS ONE 7, e40740 (2012).

14. Laing, E. D. et al. Serologic evidence of fruit bat exposure to filoviruses, Singapore, 2011-2016 Emerg. Infect. Dis. 24, 114-117 (2018).

15. Yuan, J. et al. Serological evidence of ebolavirus infection in bats, China Virol. J. 9, 236 (2012).

16. Negredo, A. et al. Discovery of an ebolavirus-like filovirus in Europe. PLOS Pathog. 7, e1002304 (2011).

17. Kemenesi, G. et al. Re-emergence of Lloviu virus in Miniopterus schreibersii bats, Hungary, 2016. Emerg. Microbes Infect. 7, 66 (2018).

18. Goldstein, T. et al. The discovery of Bombali virus adds further support for bats as hosts of ebolaviruses. Nat Microbiol. 3, 1084-1089 (2018).

19. Yang, X. L. et al. Genetically diverse filoviruses in Rousettus and Eonycteris spp. Bats, China, 2009 and 2015. Emerg. Infect. Dis. 23, 482-486 (2017).

20. Shi, M. et al. The evolutionary history of vertebrate RNA viruses. Nature 556, 197-202 (2018).
21. Mayhoub, A. S. \& Hepatitis, C. RNA-dependent, RNA polymerase inhibitors: a review of structure-activity and resistance relationships; different scaffolds and mutations. Bioorg. Med. Chem. 20, 3150-3161 (2012).

22. Zumla, A. et al. Host-directed therapies for infectious diseases: current status, recent progress, and future prospects. Lancet Infect. Dis. 16, e47-e63 (2016).

23. De Clercq, E. \& Li, G. Approved antiviral drugs over the past 50 years. Clin. Microbiol. Rev. 29, 695-747 (2016).

24. CenterWatch. 2019 FDA approved drugs. CenterWatch https://www.centerwatch.com/drug-information/fdaapproved-drugs (2019).

25. Bausch, D. G. \& Rojek, A. West Africa 2013: re-examining Ebola. Microbiol. Spectr. 4, El10-00222016 (2016).

26. Elmahdawy, M. et al. Ebola virus epidemic in West Africa: global health economic challenges, lessons learned, and policy recommendations. Value Health Reg. Issues 13, 67-70 (2017).

27. Cross, R. W., Mire, C. E., Feldmann, H. \& Geisbert, T. W. Post-exposure treatments for Ebola and Marburg virus infections. Nat. Rev. Drug Discov. 17, 413-434 (2018).

28. World Health Organization. Clinical management of patients with viral haemorrhagic fever: a pocket guide for front-line health workers. WHO http://apps.who. int/iris/bitstream/handle/10665/205570/97892415 49608_eng.pdf (2016). 
29. Rojek, A., Horby, P. \& Dunning, J. Insights from clinical research completed during the west Africa Ebola virus disease epidemic. Lancet Infect. Dis. 17, e280-e292 (2017).

30. Richardson, T., Johnston, A. M. \& Draper, H. A Systematic review of Ebola treatment trials to assess the extent to which they adhere to ethical guidelines. PLOS ONE 12, e0168975 (2017).

The Review provides a critical discussion about the ethical requirements for clinical studies of antivirals against filoviruses

31. Maxmen, A. Experimental Ebola drugs face tough test in war zone. Nature 561, 14 (2018).

32. US National Library of Medicine. ClinicalTrials.go https://clinicaltrials.gov/ct2/show/NCT03719586 (2019)

33. Henao-Restrepo, A. M. et al. Efficacy and effectiveness of an rVSV-vectored vaccine in preventing Ebola virus disease: final results from the Guinea ring vaccination, open-label, cluster-randomised trial (Ebola Ca Suffit!). Lancet 389, 505-518 (2017).

A clinical trial showing efficacy of the recombinant vesicular stomatitis virus-EBOV vaccine.

34. World Health Organization. Preliminary results on the efficacy of rVSV-ZEBOV-GP Ebola vaccine using the ring vaccination strategy in the control of an Ebola outbreak in the Democratic Republic of the Congo: an example of integration of research into epidemic response. WHO https://www.who.int/csr/resources/ publications/ebola/ebola-ring-vaccination-results-12april-2019.pdf (2019).

35. Martin, S, et al. A genome-wide siRNA screen identifies a druggable host pathway essential for the Ebola virus life cycle. Genome Med. 10, 58 (2018).

36. Lee, N. et al. High-throughput drug screening using the Ebola virus transcription- and replicationcompetent virus-like particle system. Antiviral Res. 158, 226-237 (2018). This article illustrates the power of life cycle modelling systems for antiviral screening

37. Luthra, P. et al. A high throughput screen identifies benzoquinoline compounds as inhibitors of Ebola virus replication. Antiviral Res. 150, 193-201 (2018).

38. Luthra, P. et al. Inhibiting pyrimidine biosynthesis impairs Ebola virus replication through depletion of nucleoside pools and activation of innate immune responses. Antiviral Res. 158, 288-302 (2018).

39. Nelson, E. A. et al. Clomiphene and its isomers block Ebola virus particle entry and infection with similar potency: potential therapeutic implications. Viruses $\mathbf{8}$ E206 (2016).

40. Nelson, E. A. et al. The phosphatidylinositol-3phosphate 5-kinase inhibitor apilimod blocks filoviral entry and infection. PLOS Negl Trop. Dis. 11, e0005540 (2017).

41. Hoenen, T., Groseth, A., Callison, J., Takada, A \& Feldmann, H. A novel Ebola virus expressing luciferase allows for rapid and quantitative testing of antivirals. Antiviral Res. 99, 207-213 (2013).

42. Johansen, L. M. et al. A screen of approved drugs and molecular probes identifies therapeutics with anti-Ebola virus activity. Sci. Transl Med. 7, 290ra89 (2015).

This work is one of the few examples in which infectious virus was used in an antiviral screen.

43. Towner, J. S. et al. Generation of eGFP expressing recombinant Zaire ebolavirus for analysis of early pathogenesis events and high-throughput antiviral drug screening. Virology 332, 20-27 (2005).

44. Yamaoka, S., Banadyga, L., Bray, M. \& Ebihara, H. Small animal models for studying filovirus pathogenesis. Curr. Top. Microbiol. Immunol. 411 195-227 (2017).

45. Cross, R. W., Fenton, K. A. \& Geisbert, T. W. Small animal models of filovirus disease: recent advances and future directions. Expert Opin. Drug Discov. 13 , 1027-1040 (2018)

46. Banadyga, L., Dolan, M. A. \& Ebihara, H. Rodentadapted filoviruses and the molecular basis of pathogenesis. J. Mol. Biol. 428, 3449-3466 (2016).

47. Sugita, Y., Matsunami, H., Kawaoka, Y., Noda, T. $\&$ Wolf, M. Cryo-EM structure of the Ebola virus nucleoprotein-RNA complex at 3.6 A resolution. Nature 563, 137-140 (2018).

48. Bharat, T. A. et al. Structural dissection of Ebola virus and its assembly determinants using cryo-electron tomography. Proc. Natl Acad. Sci. USA 109, 4275-4280 (2012)

49. Noda, T. et al. Ebola virus VP40 drives the formation of virus-like filamentous particles along with GP. J. Virol. 76, 4855-4865 (2002).
50. Volchkov, V. E., Feldmann, H., Volchkova, V. A. \& Klenk, H. D. Processing of the Ebola virus glycoprotein by the proprotein convertase furin. Proc. Natl Acad. Sci. USA 95, 5762-5767 (1998).

51. Becker, S., Spiess, M. \& Klenk, H. D. The asialoglycoprotein receptor is a potential liver-specific receptor for Marburg virus. J. Gen. Virol. 76 393-399 (1995)

52. Takada, A. et al. Human macrophage C-type lectin specific for galactose and $\mathrm{N}$-acetylgalactosamine promotes filovirus entry. J. Virol. 78, 2943-2947 (2004).

53. Simmons, G. et al. DC-SIGN and DC-SIGNR bind Ebola glycoproteins and enhance infection of macrophages and endothelial cells. Virology 305, 115-123 (2003).

54. Alvarez, C. P. et al. C-Type lectins DC-SIGN and L-SIGN mediate cellular entry by Ebola virus in cis and in trans. J. Virol. 76, 6841-6844 (2002).

55. Takada, A. et al. Downregulation of beta 1 integrins by Ebola virus glycoprotein: implication for virus entry. Virology 278, 20-26 (2000)

56. Chan S. Y et al. Folate receptor-alpha is a cofactor for cellular entry by Marburg and Ebola viruses. Cell 106 $117-126$ (2001)

57. Shimojima, M. et al. Tyro3 family-mediated cell entry of Ebola and Marburg viruses. J. Virol. 80 10109-10116 (2006)

58. Kondratowicz, A. S. et al. T cell immunoglobulin and mucin domain 1 (TIM-1) is a receptor for Zaire Ebolavirus and Lake Victoria Marburgvirus. Proc. Nat Acad. Sci. USA 108, 8426-8431 (2011).

59. Nanbo, A. \& Kawaoka, Y. Molecular mechanism of externalization of phosphatidylserine on the surface of Ebola virus particles. DNA Cell Biol. 38, 115-120 (2019).

60. Moller-Tank, S., Kondratowicz, A. S., Davey, R. A., Rennert, P. D. \& Maury, W. Role of the phosphatidylserine receptor TIM-1 in enveloped-virus entry. J. Virol. 87, 8327-8341 (2013).

61. Aleksandrowicz, P. et al. Ebola virus enters host cells by macropinocytosis and clathrin-mediated endocytosis J. Infect. Dis. 204 (Suppl. 3), S957-S967 (2011).

62. Nanbo, A. et al. Ebolavirus is internalized into host cells via macropinocytosis in a viral glycoproteindependent manner. PLOS Pathog. 6, e100112 (2010).

63. Chandran, K., Sullivan, N. J., Felbor, U., Whelan, S. P. \& Cunningham, J. M. Endosomal proteolysis of the Ebola virus glycoprotein is necessary for infection. Science 308, 1643-1645 (2005).

64. Ng, M. et al. Cell entry by a novel European filovirus requires host endosomal cysteine proteases and Niemann-Pick C1. Virology 468-470, 637-646 (2014).

65. Carette, J. E. et al. Ebola virus entry requires the cholesterol transporter Niemann-Pick C1. Nature 477, 340-343 (2011).

66. Cote, M. et al. Small molecule inhibitors reveal Niemann-Pick $C 1$ is essential for Ebola virus infection. Nature 477, 344-348 (2011).

67. King, L. B. et al. The Marburgvirus-neutralizing human monoclonal antibody MR191 targets a conserved site to block virus receptor binding. Cell Host Microbe 23 , 101-109 (2018)

68. Sakurai, Y. et al. Ebola virus. Two-pore channels control Ebola virus host cell entry and are drug targets for disease treatment. Science 347, 995-998 (2015).

69. Simmons, J. A. et al. Ebolavirus glycoprotein directs fusion through NPC $1^{+}$endolysosomes. J. Virol. 90, 605-610 (2016)

70. Banadyga, L. et al. Ebola virus VP24 interacts with NP to facilitate nucleocapsid assembly and genome packaging. Sci. Rep. 7, 7698 (2017).

71. Watt, A. et al. A novel life cycle modeling system for Ebola virus shows a genome length-dependent role of VP24 in virus infectivity. J. Virol. 88, 10511-10524 (2014).

72. Muhlberger, E., Weik, M., Volchkov, V. E., Klenk, H. D. $\varangle$ Becker, S. Comparison of the transcription and replication strategies of marburg virus and Ebola virus by using artificial replication systems. J. Virol. 73 , 2333-2342 (1999)

73. Muhlberger, E., Lotfering, B., Klenk, H. D. \& Becker, S. Three of the four nucleocapsid proteins of Marburg virus, NP, VP35, and L, are sufficient to mediate replication and transcription of Marburg virus-specific monocistronic minigenomes. J. Virol. 72, 8756-8764 (1998).

74. Enterlein, S. et al. Rescue of recombinant Marburg virus from CDNA is dependent on nucleocapsid protein VP30. J. Virol. 80, 1038-1043 (2006).
75. Hoenen, T. et al. Inclusion bodies are a site of ebolavirus replication. J. Virol. 86, 11779-11788 (2012).

76. Lier, C., Becker, S. \& Biedenkopf, N. Dynamic phosphorylation of Ebola virus VP30 in NP-induced inclusion bodies. Virology 512, 39-47 (2017).

77. Mehedi, M. et al. A new Ebola virus nonstructural glycoprotein expressed through RNA editing. J. Virol. 85, 5406-5414 (2011)

78. Volchkov, V. E. et al. GP mRNA of Ebola virus is edited by the Ebola virus polymerase and by $\mathrm{T} 7$ and vaccinia virus polymerases. Virology 214, 421-430 (1995).

79. Takahashi, K. et al. DNA topoisomerase 1 facilitates the transcription and replication of the Ebola virus genome. J. Virol. 87, 8862-8869 (2013). This study provides evidence for the involvement of a component of the host cell DNA replicative machinery, TOP1, in EBOV RNA synthesis.

80. Fang, J. et al. Staufen 1 interacts with multiple components of the Ebola virus ribonucleoprotein and enhances viral RNA synthesis. mBio 9, e01771-18 (2018).

81. Biedenkopf, N., Hartlieb, B., Hoenen, T. \& Becker, S. Phosphorylation of Ebola virus VP30 influences the composition of the viral nucleocapsid complex: impact on viral transcription and replication. J. Biol. Chem. 288, 11165-11174 (2013).

82. Modrof, J., Muhlberger, E., Klenk, H. D. \& Becker, S. Phosphorylation of VP30 impairs ebola virus transcription. J. Biol. Chem. 277, 33099-33104 (2002).

83. Kruse, T. et al. The Ebola virus nucleoprotein recruits the host PP2A-B56 phosphatase to activate transcriptional support activity of VP30. Mol. Cell 69 136-145 (2018)

This article describes a competitive inhibitor that prevents the PP2A-NP association to regulate VP30 phosphorylation.

84. Batra, J. et al. Protein interaction mapping identifies RBBP6 as a negative regulator of Ebola virus replication. Cell 175, 1917-1930 (2018).

85. Ammosova, T. et al. Protein phosphatase 1-targeting small-molecule C31 inhibits Ebola virus replication. J. Infect. Dis. 218 (Suppl. 5), S627-S635 (2018).

86. Schudt, G. et al. Transport of ebolavirus nucleocapsids is dependent on actin polymerization: live-cell imaging analysis of Ebolavirus-infected cells. J. Infect. Dis. 212 (Suppl. 2), S160-S166 (2015).

87. Takamatsu, Y., Kolesnikova, L. \& Becker, S. Ebola virus proteins NP, VP35, and VP24 are essential and sufficient to mediate nucleocapsid transport. Proc. Natl Acad. Sci. USA 115, 1075-1080 (2018).

88. Adu-Gyamfi, E., Digman, M. A., Gratton, E. $\delta$ Stahelin, R. V. Single-particle tracking demonstrates that actin coordinates the movement of the Ebola virus matrix protein. Biophys. J. 103, L41-43 (2012).

89. Han, Z. \& Harty, R. N. Packaging of actin into Ebola virus VLPs. Virol. J. 2, 92 (2005)

90. Ruthel, G. et al. Association of Ebola virus matrix protein VP40 with microtubules. J. Virol. 79 4709-4719 (2005)

91. Noda, T. et al. Assembly and budding of Ebolavirus. PLOS Pathog. 2, e99 (2006).

92. Lu, J. et al. Host IQGAP1 and Ebola virus VP40 interactions facilitate virus-like particle egress. J. Virol. 87, 7777-7780 (2013)

93. Yamayoshi, S. et al. Ebola virus matrix protein VP40 uses the COPII transport system for its intracellular transport. Cell Host Microbe 3, 168-177 (2008).

94. Feldmann, H., Nichol, S. T., Klenk, H. D., Peters, C. J. $\&$ Sanchez, A. Characterization of filoviruses based on differences in structure and antigenicity of the virion glycoprotein. Virology 199, 469-473 (1994).

95. Wool-Lewis, R. J. \& Bates, P. Endoproteolytic processing of the ebola virus envelope glycoprotein: cleavage is not required for function. J. Virol. 73, 1419-1426 (1999).

96. Neumann, G., Feldmann, H., Watanabe, S Lukashevich, I. \& Kawaoka, Y. Reverse genetics demonstrates that proteolytic processing of the Ebola virus glycoprotein is not essential for replication in cell culture. J. Virol. 76, 406-410 (2002).

97. Martin-Serrano, J., Zang, T. \& Bieniasz, P. D. HIV-1 and Ebola virus encode small peptide motifs that recruit Tsg 101 to sites of particle assembly to facilitate egress. Nat. Med. 7, 1313-1319 (2001).

98. Licata, J. M. et al. Overlapping motifs (PTAP and PPEY) within the Ebola virus VP40 protein function independently as late budding domains: involvement of host proteins TSG101 and VPS-4. J. Virol. 77. 812-1819 (2003). 
99. Han, Z. et al. ITCH E3 ubiquitin ligase interacts with Ebola virus VP40 to regulate budding. J. Virol. 90 , 9163-9171 (2016).

100. Harty, R. N., Brown, M. E., Wang, G., Huibregtse, J. \& Hayes, F. P. A. PPxY motif within the VP40 protein of Ebola virus interacts physically and functionally with a ubiquitin ligase: implications for filovirus budding. Proc. Natl Acad. Sci. USA 97, 13871-13876 (2000).

101. Kolesnikova, L., Mittler, E., Schudt, G., Shams-Eldin, H. \& Becker, S. Phosphorylation of Marburg virus matrix protein VP40 triggers assembly of nucleocapsids with the viral envelope at the plasma membrane. Cell. Microbiol. 14, 182-197 (2012).

102. Nanbo, A. et al. Ebola virus requires a host scramblase for externalization of phosphatidylserine on the surface of viral particles. PLOS Pathog. 14, e1006848 (2018)

103. Zeitlin, L. et al. Antibody therapeutics for Ebola virus disease. Curr. Opin. Virol. 17, 45-49 (2016).

104. Dye, J. M. et al. Postexposure antibody prophylaxis protects nonhuman primates from filovirus disease. Proc. Natl Acad. Sci. USA 109, 5034-5039 (2012).

105. Qiu, X. et al. Reversion of advanced Ebola virus disease in nonhuman primates with ZMapp. Nature 514, 47-53 (2014)

106. Davey, R. T. Jr et al. A randomized, controlled trial of ZMapp for Ebola virus infection. N. Engl. J. Med. 375 1448-1456 (2016)

\section{This study describes the clinical trial of ZMapp.}

107. King, L. B., West, B. R., Schendel, S. L. \& Saphire, E. O. The structural basis for filovirus neutralization by monoclonal antibodies. Curr. Opin. Immunol. 53 196-202 (2018)

108. Pallesen, J. et al. Structures of Ebola virus GP and sGP in complex with therapeutic antibodies. Nat. Microbiol. 1, 16128 (2016).

The study reports the structural analysis of ZMapp antibodies in complex with their viral target

109. Tran, E. E. et al. Mapping of Ebolavirus neutralization by monoclonal antibodies in the ZMapp cocktail using cryo-electron tomography and studies of cellular entry. J. Virol. 90, 7618-7627 (2016).

110. Olinger, G. G. Jr et al. Delayed treatment of Ebola virus infection with plant-derived monoclonal antibodies provides protection in rhesus macaques. Proc. Natl Acad. Sci. USA 109, 18030-18035 (2012).

111. Corti, D. et al. Protective monotherapy against lethal Ebola virus infection by a potently neutralizing antibody. Science 351, 1339-1342 (2016).

112. Misasi, J. et al. Structural and molecular basis for Ebola virus neutralization by protective human antibodies. Science 351, 1343-1346 (2016).

113. Sivapalasingam, S. et al. Safety, pharmacokinetics, and immunogenicity of a co-formulated cocktail of three human monoclonal antibodies targeting Ebola virus glycoprotein in healthy adults: a randomised, first-in-human phase 1 study. Lancet Infect. Dis. 18 884-893 (2018)

114. Saphire, E. O. et al. Systematic analysis of monoclonal antibodies against Ebola virus GP defines features that contribute to protection. Cell 174, 938-952 (2018).

115. West, B. R. et al. Structural basis of pan-Ebolavirus neutralization by a human antibody against a conserved yet cryptic epitope. mBio 9, e01674-18 (2018).

116. Janus, B. M. et al. Structural basis for broad neutralization of ebolaviruses by an antibody targeting the glycoprotein fusion loop. Nat. Commun. 9, 3934 (2018).

117. Pettit, D. K. et al. CHO cell production and sequence improvement in the 13C6FR1 anti-Ebola antibody. MAbs 8, 347-357 (2016).

118. Kugelman, J. R. et al. Emergence of Ebola virus escape variants in infected nonhuman primates treated with the MB-003 antibody cocktail. Cell Rep. 12, 2111-2120 (2015).

119. Hoenen, T. \& Feldmann, H. Reverse genetics systems as tools for the development of novel therapies against filoviruses. Expert Rev. Anti Infect. Ther. 12 1253-1263 (2014)

120. Anantpadma, M. et al. Large-scale screening and identification of novel Ebola virus and Marburg Virus entry inhibitors. Antimicrob. Agents Chemother. 60, 4471-4481 (2016)

121. Dyall, J. et al. Identification of combinations of approved drugs with synergistic activity against Ebola virus in cell cultures. J. Infect. Dis. 218 (Suppl. 5), S672-S678 (2018) This is one of the few studies exploring the synergistic potential of antivirals against filoviruses.
122. Bekerman, E. et al. Anticancer kinase inhibitors impair intracellular viral trafficking and exert broad-spectrum antiviral effects. J. Clin. Invest. 127, 1338-1352 (2017).

123. van der Linden, W. A. et al. Cysteine cathepsin inhibitors as anti-Ebola agents. ACS Infect. Dis. 2 173-179 (2016).

124. Liu, H. et al. Identification of potent Ebola virus entry inhibitors with suitable properties for in vivo studies. J. Med. Chem. 61, 6293-6307 (2018).

125. Zhao, Y. et al. Toremifene interacts with and destabilizes the Ebola virus glycoprotein. Nature 535 169-172 (2016)

126. Johansen, L. M. et al. FDA-approved selective estrogen receptor modulators inhibit Ebola virus infection. Sci. Transl Med. 5, 190ra79 (2013).

127. Fan, H. et al. Selective inhibition of Ebola entry with selective estrogen receptor modulators by disrupting the endolysosomal calcium. Sci. Rep. 7, 41226 (2017).

128. McCarthy, S. D. et al. A rapid screening assay identifies monotherapy with interferon-ss and combination therapies with nucleoside analogs as effective inhibitors of Ebola virus. PLOS Negl. Trop. Dis 10, e0004364 (2016).

129. Sun, W. et al. Synergistic drug combination effectively blocks Ebola virus infection. Antiviral Res. 137 165-172 (2017)

130. Shrivastava-Ranjan, P. et al. Statins suppress Ebola virus infectivity by interfering with glycoprotein processing. $m$ Bio 9, e00660-18 (2018).

131. Geisbert, T. W. et al. Postexposure protection of non-human primates against a lethal Ebola virus challenge with RNA interference: a proof-of-concept study. Lancet 375, 1896-1905 (2010).

132. Iversen, P. L. et al. Discovery and early development of AVI-7537 and AVI-7288 for the treatment of Ebola virus and Marburg virus infections. Viruses 4 2806-2830 (2012).

133. Groseth, A. et al. In vitro evaluation of antisense RNA efficacy against filovirus infection, by use of reverse genetics. J. Infect. Dis. 196 (Suppl. 2), S382-S389 (2007).

134. Filone, C. M. et al. Identification of a broad-spectrum inhibitor of viral RNA synthesis: validation of a prototype virus-based approach. Chem. Biol. 20 , 424-433 (2013).

135. Easton, V. et al. Identification of a small molecule inhibitor of Ebola virus genome replication and transcription using in silico screening. Antiviral Res. 156, 46-54 (2018).

This article describes the structure-guided design of an NP interaction inhibitor

136. Warren, T. K. et al. Therapeutic efficacy of the small molecule GS-5734 against Ebola virus in rhesus monkeys. Nature 531, 381-385 (2016)

137. Taylor, R. et al. BCX4430 - a broad-spectrum antiviral adenosine nucleoside analog under development for the treatment of Ebola virus disease. J. Infect. Public Health 9, 220-226 (2016).

138. Reynard, O. et al. Identification of a new ribonucleoside inhibitor of Ebola virus replication. Viruses 7, 6233-6240 (2015)

139. Guedj, J. et al. Antiviral efficacy of favipiravir against Ebola virus: a translational study in cynomolgus macaques. PLOS Med. 15, e1002535 (2018).

140. Lo, M. K. et al. Susceptibility of paramyxoviruses and filoviruses to inhibition by 2 '-monofluoro- and 2 '-difluoro-4'-azidocytidine analogs. Antiviral Res. 153, 101-113 (2018).

141. Tong, X. et al. Merimepodib, an IMPDH inhibitor, suppresses replication of Zika virus and other emerging viral pathogens. Antiviral Res. 149, 34-40 (2018).

142. Jin, Z., Smith, L. K., Rajwanshi, V. K., Kim, B. $\&$ Deval, J. The ambiguous base-pairing and high substrate efficiency of T-705 (Favipiravir) Ribofuranosy 5'-triphosphate towards influenza A virus polymerase. PLOS ONE 8, e68347 (2013).

143. Furuta, Y. et al. Mechanism of action of T-705 against influenza virus. Antimicrob. Agents Chemother. 49, 981-986 (2005)

144. Eriksson, B. et al. Inhibition of influenza virus ribonucleic acid polymerase by ribavirin triphosphate Antimicrob. Agents Chemother. 11, 946-951 (1977).

145. Tchesnokov, E. P., Feng, J. Y., Porter, D. P. \& Gotte, M. Mechanism of inhibition of Ebola virus RNA-dependent RNA polymerase by remdesivir. Viruses 11, E326 (2019).

146. Lo, M. K. et al. GS-5734 and its parent nucleoside analog inhibit Filo-, Pneumo-, and Paramyxoviruses. Sci. Rep. 7, 43395 (2017)
147. Gabriel, G. et al. Importin-alpha7 is involved in the formation of Ebola virus inclusion bodies but is not essential for pathogenicity in mice. J. Infect. Dis. 212 (Suppl. 2), S316-S321 (2015).

148. Nelson, E. V. et al. Ebola virus does not induce stress granule formation during infection and sequesters stress granule proteins within viral inclusions. J. Virol. 90, 7268-7284 (2016).

149. Dunning, J. et al. Experimental treatment of Ebola virus disease with TKM-130803: a single-arm phase 2 clinical trial. PLOS Med. 13, e1001997 (2016).

150. Sissoko, D. et al. Experimental treatment with favipiravir for Ebola virus disease (the JIKI Trial): a historically controlled, single-arm proof-of-concept trial in Guinea. PLOS Med. 13, e1001967 (2016).

151. Bai, C. Q. et al. Clinical and virological characteristics of Ebola virus disease patients treated with favipiravir (T-705)-Sierra Leone, 2014. Clin. Infect. Dis. 63, 1288-1294 (2016).

152. Mudhasani, R. et al. High content image-based screening of a protease inhibitor library reveals compounds broadly active against Rift Valley fever virus and other highly pathogenic RNA viruses. PLOS Negl. Trop. Dis. 8, e3095 (2014).

153. Garcia, M. et al. Productive replication of Ebola virus is regulated by the c-Abl1 tyrosine kinase. Sci. Trans/ Med. 4, 123 ra24 (2012).

154. Kolesnikova, L., Nanbo, A., Becker, S. \& Kawaoka, Y. Inside the cell: assembly of filoviruses. Curr. Top. Microbiol. Immunol. 411, 353-380 (2017).

155. Wendt, L., Kamper, L., Schmidt, M. L., Mettenleiter, T. C. $\&$ Hoenen, T. Analysis of a putative late domain using an Ebola virus transcription and replication-competent virus-like particle system. J. Infect. Dis. 218 (Suppl. 5), S355-S359 (2018).

156. Bornholdt, Z. A. et al. Structural rearrangement of ebola virus VP40 begets multiple functions in the virus life cycle. Cell 154, 763-774 (2013). This article describes the detailed structura analysis of VP40 and the identification of molecular targets for inhibitors of morphogenesis and/or budding.

157. Hoenen, T. et al. Oligomerization of Ebola virus VP40 is essential for particle morphogenesis and regulation of viral transcription. J. Virol. 84, 7053-7063 (2010).

158. Jouvenet, N. et al. Broad-spectrum inhibition of retroviral and filoviral particle release by tetherin. J. Virol. 83, 1837-1844 (2009)

159. Kaletsky, R. L., Francica, J. R., Agrawal-Gamse, C. $\&$ Bates, P. Tetherin-mediated restriction of filovirus budding is antagonized by the Ebola glycoprotein. Proc. Natl Acad. Sci. USA 106, 2886-2891 (2009)

160. Vande Burgt, N. H., Kaletsky, R. L. \& Bates, P. Requirements within the Ebola viral glycoprotein for tetherin antagonism. Viruses 7, 5587-5602 (2015).

161. Radoshitzky, S. R. et al. Infectious Lassa virus, but not filoviruses, is restricted by BST-2/tetherin. J. Virol. 84 10569-10580 (2010).

162. Kuhl, A. et al. The Ebola virus glycoprotein and HIV-1 Vpu employ different strategies to counteract the antiviral factor tetherin. J. Infect. Dis. 204 (Suppl. 3), S850-S860 (2011)

163. Gonzalez-Hernandez, M. et al. A GXXXA motif in the transmembrane domain of the Ebola virus glycoprotein is required for tetherin antagonism. J. Virol. 92, e00403-18 (2018).

164. World Health Organization. Ebola virus disease: Democratic Republic of the Congo: external situation report 40. WHO https://apps.who.int/iris/bitstream/ handle/10665/312264/SITREP EVD DRC 20190507eng.pdf (2019)

165. Marzi, A. \& Mire, C. E. Current Ebola virus vaccine progress. BioDrugs 33, 9-14 (2019).

166. Reynolds, P. \& Marzi, A. Ebola and Marburg virus vaccines. Virus Genes 53, 501-515 (2017).

167. Martins, K. A., Jahrling, P. B., Bavari, S. \& Kuhn, J. H. Ebola virus disease candidate vaccines under evaluation in clinical trials. Expert Rev. Vaccines 15, 1101-1112 (2016)

168. Feldmann, H., Feldmann, F. \& Marzi, A. Ebola: lessons on vaccine development. Annu. Rev. Microbiol. 72 423-446 (2018)

169. Hoenen, T. \& Feldmann, H. Ebolavirus in West Africa, and the use of experimental therapies or vaccines. BMC Biol. 12, 80 (2014).

170. Suder, E., Furuyama, W., Feldmann, H., Marzi, A $\&$ de Wit, E. The vesicular stomatitis virus-based Ebola virus vaccine: from concept to clinical trials. Hum. Vaccin. Immunother. 14, 2107-2113 (2018). 
171. Marzi, A. et al. Efficacy of vesicular stomatitis virus-Ebola virus postexposure treatment in rhesus macaques infected with Ebola virus Makona. J. Infect. Dis. 214, S360-S366 (2016).

172. Feldmann, H. et al. Effective post-exposure treatment of Ebola infection. PLOS Pathog. 3, e2 (2007).

173. Hoenen, T., Groseth, A., de Kok-Mercado, F., Kuhn, J. H. \& Wahl-Jensen, V. Minigenomes, transcription and replication competent virus-like particles and beyond: reverse genetics systems for filoviruses and other negative stranded hemorrhagic fever viruses. Antiviral Res. 91 , 195-208 (2011).

174. Schmidt, M. L., Tews, B. A., Groseth, A. \& Hoenen, T. Generation and optimization of a green fluorescent protein-expressing transcription and replication-competent virus-like particle system for Ebola virus. J. Infect. Dis. 218, S360-S364 (2018).

175. Steffen, I. \& Simmons, G. Pseudotyping viral vectors with emerging virus envelope proteins. Curr. Gene Ther. 16, 47-55 (2016).

176. Garbutt, M. et al. Properties of replication-competent vesicular stomatitis virus vectors expressing glycoproteins of filoviruses and arenaviruses. J. Virol. 78, 5458-5465 (2004)
177. Warfield, K. L. et al. Development and characterization of a mouse model for Marburg hemorrhagic fever J. Virol. 83, 6404-6415 (2009).

178. Bray, M., Davis, K., Geisbert, T., Schmaljohn, C. $\&$ Huggins, J. A mouse model for evaluation of prophylaxis and therapy of Ebola hemorrhagic fever. J. Infect. Dis. 178, 651-661 (1998).

179. Connolly, B. M. et al. Pathogenesis of experimental Ebola virus infection in guinea pigs. J. Infect. Dis. 179 (Suppl. 1), S203-S117 (1999).

180. Marzi, A. et al. A hamster model for Marburg virus infection accurately recapitulates Marburg hemorrhagic fever. Sci. Rep. 6, 39214 (2016).

181. Ebihara, H. et al. A Syrian golden hamster model recapitulating Ebola hemorrhagic fever. J. Infect. Dis. 207, 306-318 (2013).

182. Cross, R. W. et al. The Domestic Ferret (Mustela putorius furo) as a lethal infection model for 3 species of Ebolavirus. J. Infect. Dis. 214, 565-569 (2016).

183. Cross, R. W. et al. Marburg and Ravn viruses fail to cause disease in the Domestic Ferret (Mustela putorius furo). J. Infect. Dis. 218 (Suppl. 5), S448-S452 (2018)

184. Geisbert, T. W., Strong, J. E. \& Feldmann, H. Considerations in the use of nonhuman primate models of Ebola virus and Marburg virus infection. J. Infect. Dis. 212 (Suppl. 2), S91-S97 (2015).
185. Groseth, A. \& Hoenen, T. Forty years of Ebolavirus molecular biology: understanding a novel disease agent through the development and application of new technologies. Methods Mol. Biol. 1628, 15-38 (2017).

\section{Acknowledgements}

Work in the authors' laboratories was funded in part by the Friedrich-Loeffler-Institut and in part by the Division of Intramural Research, National Institute of Allergy and Infectious Diseases, National Institutes of Health.

\section{Author contributions}

T.H., A.G. and H.F. researched data for the article, contributed substantially to the discussion of content, wrote the article and reviewed and edited the manuscript before submission.

Competing interests

The authors declare no competing interests.

Publisher's note

Springer Nature remains neutral with regard to jurisdictional claims in published maps and institutional affiliations.

Supplementary information

Supplementary information is available for this paper at https://doi.org/10.1038/s41579-019-0233-2. 